\title{
Gut microbiota and inflammation in chronic kidney disease and their roles in the development of cardiovascular disease
}

\author{
Emine M. Onal ${ }^{1} \cdot$ Baris Afsar ${ }^{2} \cdot$ Adrian Covic $^{3} \cdot$ Nosratola D. Vaziri $^{4} \cdot$ Mehmet Kanbay $^{5}$ \\ Received: 14 February 2018 / Revised: 25 July 2018 / Accepted: 26 July 2018 / Published online: 30 November 2018 \\ (c) The Japanese Society of Hypertension 2018
}

\begin{abstract}
The health and proper functioning of the cardiovascular and renal systems largely depend on crosstalk in the gut-kidney-heart/vessel triangle. Recent evidence suggests that the gut microbiota has an integral function in this crosstalk. Mounting evidence indicates that the development of chronic kidney and cardiovascular diseases follows chronic inflammatory processes that are affected by the gut microbiota via various immune, metabolic, endocrine, and neurologic pathways. Additionally, deterioration of the function of the cardiovascular and renal systems has been reported to disrupt the original gut microbiota composition, further contributing to the advancement of chronic cardiovascular and renal diseases. Considering the interaction between the gut microbiota and the renal and cardiovascular systems, we can infer that interventions for the gut microbiota through diet and possibly some medications can prevent/stop the vicious cycle between the gut microbiota and the cardiovascular/renal systems, leading to a decrease in chronic cardiovascular and renal diseases.
\end{abstract}

Keywords Gut microbiota $\cdot$ Chronic kidney disease $\cdot$ Uremic toxins $\cdot$ Cardiovascular disease

\section{Introduction}

The internal homeostasis of the human body largely depends on the interactions between bacteria and human cells, which have a normal composition ratio of 1.3:1 [1]. The gut microbiome is the best represented group [1], with widespread effects on the functioning and pathogenesis of each system of the body, including the renal [2] and cardiovascular [3] systems.

Mehmet Kanbay

mkanbay@ku.edu.tr

drkanbay@yahoo.com

1 Department of Medicine, Koc University School of Medicine, Istanbul, Turkey

2 Department of Medicine, Division of Nephrology, Suleyman Demirel University School of Medicine, Isparta, Turkey

3 Nephrology Clinic, Dialysis and Renal Transplant Center, 'C.I. PARHON' University Hospital, and 'Grigore T. Popa' University of Medicine, Iasi, Romania

4 Division of Nephrology and Hypertension, Schools of Medicine and Biological Science, University of California, California, CA, USA

5 Department of Medicine, Division of Nephrology, Koc University School of Medicine, Istanbul, Turkey
The gut microbiota consists of $10^{14}$ bacteria [4] with tremendous diversity [5]. In healthy adults, Firmicutes and Bacteroidetes are the dominant phyla [5]. The gut microbiota contributes to the health of the host by protective and trophic functions [6] in addition to aiding host metabolism by synthesizing conjugated linoleic acid [7], amino acids such as lysine [8], vitamin B complex [9], and vitamin K [10] and by facilitating the absorption of complex carbohydrates [11]. Additionally, the gut microbiota communicates with the rest of the body primarily via its interactions with the immune system [12] and its metabolic products, such as uremic toxins [2], oxalate [13], bile acids [14], short-chain fatty acids (SCFAs) [15], nitric oxide (NO) [16], vitamin K [10], vitamin B complex [17], threonine [18], microRNAs (miRNAs) [19], gut hormones [20], neurotransmitters [21], the autonomic nervous system (ANS), and the enteric nervous system (ENS) [22] and through effects on intestinal expression of cannabinoid receptor CB1 [23].

Previous studies have demonstrated profound changes in the composition of the gut microbial community in patients and animals with chronic kidney disease (CKD) [24]. The diversity and ratio of bacterial species change in CKD and cardiovascular disease (CVD) patients, implicating possible bidirectional crosstalk between the gut microbiota and the renal and cardiovascular systems [25-27]. In fact, 
spontaneously hypertensive rats (SHRs) were found to have decreased microbial richness with an increased Firmicutes/ Bacteroidetes ratio [28], whereas end-stage renal disease (ESRD) patients were reported to have increased microbial diversity, with an increase in Firmicutes, Actinobacteria, and Proteobacteria and a decrease in Bifidobacteria and Lactobacilli [29]. A meta-analysis indicated that correction of the bacterial composition of the gut microbiota by prebiotics, probiotics, and synbiotics reduced the serum levels of uremic toxins, such as p-cresyl sulfate (p-CS) and indoxyl sulfate (IS) [30], which were found to have detrimental effects on renal and cardiovascular health [31]. Therefore, management of the gut flora through diet and medications can start a new trend in the treatment and prevention of CKD and CVD (Table 1).

\section{The gut microbiota regulates inflammatory processes directly and indirectly}

Modulation of the local and systemic inflammatory profiles is one of the mainstays of communication between the gut microbiota and the host. This "communication" takes place as direct and indirect interactions of the gut microbiota with the host, as detailed below.

The gut microbiota directly manipulates the host inflammatory response through its interactions with mucus [32] and epithelial barriers [33, 34] of the intestinal mucosa and immune cells [35]. Probiotic and commensal bacteria prevent development of local and systemic inflammation due to leakage of bacterial products, such as lipopolysaccharide (LPS), into the circulation via strengthening gut barrier function through various mechanisms $[36,37]$. Increasing the secretion of antimicrobials, such as $\beta$ defensin, secretory $\operatorname{IgA}$ [36], and NO [16], enhancing mucus production, stabilizing the tight junctions between intestinal epithelial cells (IECs) [36], and suppressing the inflammatory response from IECs [34], are among the gut barrier-strengthening mechanisms. Furthermore, the gut microbiota can indirectly reduce intestinal permeability through selectively reducing intestinal expression of CB1, which is a cannabinoid receptor found to augment gut mucosal permeability [23]. Similarly, gut permeability can be deceased by species such as Lactobacillus and Bifidobacterium through glucagon-like peptide (GLP)-2 [37]. Finally, the commensal bacteria Bacteroides fragilis [38] and Clostridia (except for pathogenic strains) [39] have been found to increase regulatory $\mathrm{T}$ (Treg) cell activity and downregulate $\mathrm{T}$ helper 17 (Th17) cell immunity, thereby contributing to a more anti-inflammatory environment. Conversely, an environment devoid of chronic intestinal inflammation with proper gut barrier function cannot be preserved during gut dysbiosis [40] since dysbiosis involves a reduction of the majority of the commensal bacteria
Table 1 Effects of the purported mediators acting on the gut microbiota-inflammatory system interaction on the host inflammatory status

\begin{tabular}{lll}
\hline Pro-inflammatory & Anti-inflammatory & Variable effect $^{\mathrm{a}}$ \\
\hline $\begin{array}{l}\text { p-cresyl sulfate } \\
{[41,42]}\end{array}$ & SCFAs [46] & miRNAs [56] \\
$\begin{array}{l}\text { Indoxyl sulfate } \\
{[43,44]}\end{array}$ & NO [47] ${ }^{\mathrm{b}}$ & Bile acids [50] \\
TMAO [45] & Vitamin K [51] & NE [63] \\
Oxalate [48, 49] & Vitamin B complex & ANS [66, 99] \\
& {$[17,52-54]$} & \\
Serotonin [62] & Threonine [55] & \\
& GLP-1 [57] & \\
& GLP-2 [58] \\
& PYY [59] & \\
& GABA [60, 61] & \\
& ACh [65] & \\
& Dopamine [64] & \\
& H $_{2}$ S [87, 88] & \\
\hline
\end{tabular}

${ }^{\text {a Some of these mediators have both pro- and anti-inflammatory effects }}$ -miRNAs: miR455 is pro-inflammatory while miR10a and miR107 are anti-inflammatory [56]

-Bile acids: Most bile acids, especially lithocholic acid (LCA), are reported to have pro-inflammatory effects by themselves, while only ursodeoxycholic acid (UDCA) has been shown to suppress inflammation [50]. On the other hand, the activation of the bile acid receptors Farnesoid X Receptor (FXR) and TGR5 have an anti-inflammatory effect [50], chenodeoxycholic acid (CDCA) being the most potent activator of FXR [83]

-NE: Activation of the $\alpha$-adrenergic receptors elicits pro-inflammatory effects while $\beta$-adrenergic receptor activity is anti-inflammatory [63]

-ANS: The parasympathetic nervous system (PNS) suppresses inflammation via activation of the ACh receptor $\alpha 7 \mathrm{nAChR}$ [66]. On the other hand, the sympathetic nervous system (SNS) can exert both pro-inflammatory (via $\alpha_{2}$-adrenergic receptors) and anti-inflammatory (via $\beta_{2}$-adrenergic receptors) effects [66], pro-inflammatory properties being more dominant [99]

-ENS: The inflammatory effects of ENS depends on the location of the intestinal macrophages they induce; the lamina propria macrophages (LpMs) are inclined to be pro-inflammatory while the muscularis macrophages tend to have an anti-inflammatory phenotype, having the anti-inflammatory $\beta 2$-adrenoceptors [67]

${ }^{b}$ Even though NO can have pro-inflammatory activity via NF- $\mathrm{B}$ activation, the number of mechanisms leading to its anti-inflammatory effects are more [47]

and an increase in certain phyla, such as Proteobacteria and Actinobacteria [28, 29], which are associated with a disturbance in the Th17/Treg balance in favor of Th17 in the intestines [35]. Moreover, Proteobacteria [29] together with TM7 bacteria are associated with a more permeable intestinal mucus barrier, which reduces the intestinal barrier performance [32].

As suggested, the gut microbiota can establish efficient crosstalk with the rest of the body through a number of mediators. Interestingly, the metabolic end products of the 
Table 2 The phyla of the gut bacteria involved in the regulation of the host inflammatory response

\begin{tabular}{|c|c|c|c|c|c|}
\hline Firmicutes & Bacteroidetes & Proteobacteria & Actinobacteria & Verrucomicrobiaceae & Fusobacteria \\
\hline Clostridium & Bacteroides & Enterobacter & Bifidobacteria & & Fusobacterium \\
\hline Lactobacillus & Prevotella & Citrobacter & Propionibacterium & & \\
\hline Streptococcus & & Escherichia & Eggerthella & & \\
\hline Enterococcus & & Proteus & Collinsella & & \\
\hline Eubacterium & & Edwardsiella & & & \\
\hline Butyrivibrio & & Acinetobacter & & & \\
\hline Megasphaera & & Oxalobacter & & & \\
\hline Roseburia & & Hafnia & & & \\
\hline Staphylococcus & & Klebsiella & & & \\
\hline Bacillus & & Morganella & & & \\
\hline Lactococcus & & Serratia & & & \\
\hline Leuconostoc & & Pseudomonas & & & \\
\hline Pediococcus & & Salmonella & & & \\
\hline Listeria & & Deltaproteobacteria & & & \\
\hline Peptostreptococcus & & Bilophila & & & \\
\hline \multicolumn{6}{|l|}{ Ruminococcus } \\
\hline \multicolumn{6}{|l|}{ Peptococcus } \\
\hline \multicolumn{6}{|l|}{ Lachnospiraceae } \\
\hline Erysipelotrichaceae & & & & & \\
\hline
\end{tabular}

gut microbiota, including p-CS [41, 42]; IS [43, 44]; trimethylamine- $N$-oxide (TMAO) [45]; ammonia [24]; SCFAs [46]; NO [47]; oxalate [48, 49] and bile acids [50]; vitamin $\mathrm{K}$ [51]; vitamin B complex [17, 52-54]; threonine [55]; miRNAs [56]; gut hormones such as GLP-1, GLP-2, and peptide YY (PYY) [57-59]; neurotransmitters such as $\gamma$-aminobutyric acid (GABA), serotonin, norepinephrine (NE), dopamine (DA), and acetylcholine (Ach) [60-65]; the ANS [66]; and the ENS [67] have all been reported to influence the host inflammatory status. Taken together, these findings suggest that the gut microbiota is able to manipulate the inflammatory status of the host indirectly through an array of mechanisms (Tables 1 and 2).

The gut microbiota has different elements that control the production of metabolic and endocrine mediators and the activity of neurologic mediators, which are able to manipulate host inflammatory activity.

- In the case of metabolic mediators, species mostly belonging to Proteobacteria and some bacteria from the Firmicutes family produce pro-inflammatory uremic toxins [41-45, 68-71], whereas anti-inflammatory mediators, such as SCFAs and NO [46, 47], are produced by Lactobacilli and some other beneficial species belonging to the Firmicutes family, some species from the Bacteroides family, such as Bacteroides fragilis and Prevotellaceae, and Bifidobacteria [16, 71-75].

- The species producing SCFAs are also beneficial in terms of endocrine mediators, because SCFAs stimulate enteroendocrine cells to produce anti-inflammatory gut hormones, such as GLP-1, GLP-2, and PYY [57-59, 76-79].

- Likewise, other anti-inflammatory metabolic elements, including vitamin $\mathrm{K}$ and the group B vitamins [17, 5154], are produced by these beneficial bacteria, although some species from the Proteobacteria family can contribute to their production [80-82].

- The beneficial bacteria, such as Lactobacilli and Bifidobacteria, are among the species producing chenodeoxycholic acid (CDCA), which is the most potent ligand of the anti-inflammatory Farnesoid $\mathrm{X}$ receptor $[50,83,84]$ and has anti-inflammatory effects on renal tissue [85], and ursodeoxycholic acid (UDCA), which is an important anti-inflammatory bile acid [50] produced by Bifidobacteria [84]. In contrast, the pro-inflammatory bile acids DCA and lithocholic acid (LCA) [50] are mainly by-products of bile acid metabolism by species from genus Clostridium [84].

- Sulfur-reducing species from Proteobacteria produce $\mathrm{H}_{2} \mathrm{~S}$ [86], which is a strong anti-inflammatory gaseous signaling molecule [87] with renoprotective [88] and cardioprotective effects [89].

- Different neurotransmitters are produced by different bacteria; some Lactobacillus and Bifidobacteria species produce the anti-inflammatory neurotransmitters GABA and Ach, whereas some species from the Proteobacteria and Firmicutes families produce the pro-inflammatory neurotransmitter serotonin $[60,61,65]$. 


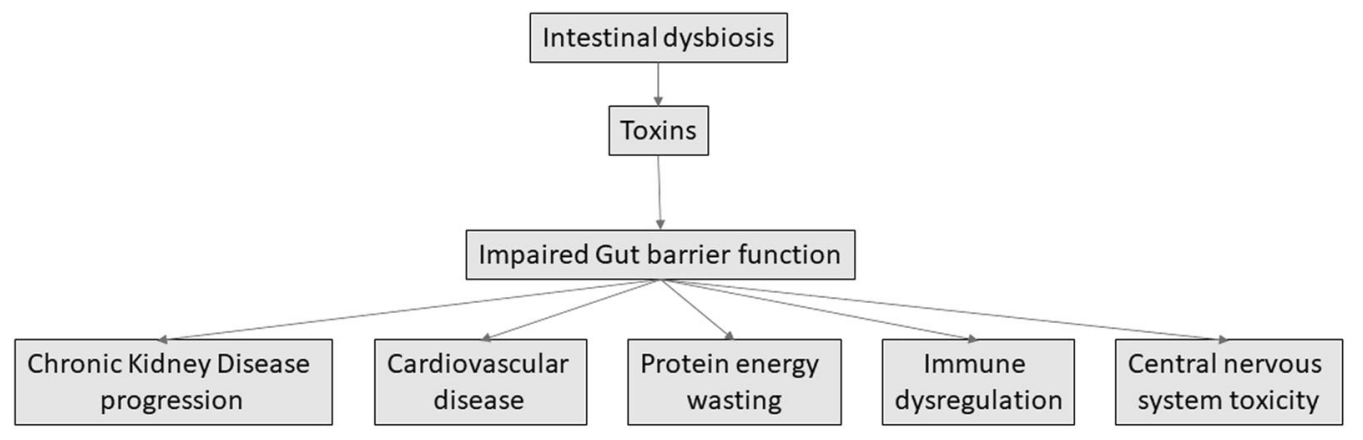

Fig. 1 Impact of dysbiosis on chronic kidney disease

- ANS activity can be modulated by the gut microbiota. A strain of Lactobacillus has been found to have inhibitory effects on renal sympathetic activity [90], and species from Lactobacilli and Bifidobacteria can indirectly reduce sympathetic activity through their analgesic and anxiolytic effects [91-96]. Furthermore, lactobacilli can induce the vagus nerve, which is known to have important anti-inflammatory effects [93, 97]. Conversely, SCFAs have stimulatory effects on the SNS [98], implying that all SCFA-producing bacteria can have a positive effect on SNS activity, which is inclined to be more pro-inflammatory [99]. However, since some Lactobacilli themselves reduce sympathetic activity [90] and induce vagal activity [93, 97] and SCFAs have overall anti-inflammatory effects [46], the production of a pro-inflammatory effect elicited by SCFA-producing bacteria through SNS activity is unlikely.

- Lastly, ENS activity is modulated by the gut microbiota; sulfur-reducing species from the Proteobacteria family increase ENS activity [86, 100], whereas Bifidobacterium longum has the opposite effect on the ENS [92]. Given that the lamina propria macrophages (LpMs) induced by the ENS tend to have pro-inflammatory effects [67], increased ENS activity by sulfur-reducing Proteobacteria itself may induce mucosal inflammation via LpM activity.

All in all, different groups of bacteria can be inferred to affect host inflammatory activity in different ways. For instance, the Bacteroides family, Bifidobacteria, Lactobacilli, and other species from the Firmicutes family mostly reduce inflammation, whereas species from Proteobacteria tend to be pro-inflammatory via metabolic, endocrine, and neurologic pathways (Table 2 and Fig. 1).

\section{Gut-kidney crosstalk and inflammation in the development of CKD}

Gut-kidney crosstalk, which is largely affected by the gut microbiota, plays an integral role in the development of CKD with reciprocal interactions [25]. The gut microbiota manipulates the processes leading to CKD through inflammatory [25], endocrine [20], and neurologic pathways [90]; a healthy gut microbiota protects the CKD, whereas gut dysbiosis contributes to the development of CKD [2]. In fact, CKD is associated with alterations in the gut microbiota; species producing uremic toxins, such as Enterobacteriaceae, Clostridiaceae, Pseudomonadaceae, and Bacteroidiaceae, are increased, whereas beneficial species, such as Lactobacillaceae, Bifidobacteriaceae, and Prevotellaceae, are decreased [101-104]. Consistently, fecal transplantation from CKD patients to antibiotic-treated mice results in an increase in the plasma TMAO levels [29]. In contrast, deterioration of kidney function disrupts the intestinal mucosal barrier and contributes to gut dysbiosis [25]. Therefore, CKD may plausibly result in a faulty bidirectional interaction between the gut microbiota and the kidneys.

As evidenced by many studies, including the Chronic Renal Insufficiency Cohort (CRIC) study, CKD is an outcome of chronic systemic inflammation [105, 106], which renders inflammation as one of the main crosstalk pathways between the gut microbiota and the kidney involved in the development in CKD. Given that gut dysbiosis accompanies CKD, we can speculate that gut dysbiosis supports a more pro-inflammatory environment in the host that eventually contributes to CKD progression. Generally, the species found to be increased in the gut flora of CKD patients tend to increase the host inflammatory response via a number of mechanisms. For example, these species generate the established pro-inflammatory substances uremic toxins [41-45, 68-71], DCA, and LCA [50, 84] and degrade the anti-inflammatory renoprotective neurotransmitter Ach [65, 107, 108]. Moreover, Proteobacteria, which is the phylum containing Pseudomonadaceae, have been found to deteriorate gut mucosal barrier function by increasing gut mucus permeability [32] and the intestinal Th17/Treg ratio [35]. Conversely, the species found to be decreased in CKD are among those that strengthen gut barrier function [16, 36, 37]; produce anti-inflammatory 
SCFAs [46, 71, 73, 109], NO [16, 47], CDCA, UDCA [50, 83-85], GABA [60, 61, 110], Ach [65, 107, 108], and the vitamin B complex [17, 52-54, 81, 82]; increase the production of gut hormones with anti-inflammatory properties [57-59, 76-79]; increase anti-inflammatory vagal activity [90, 93, 97]; and decrease pro-inflammatory renal sympathetic activity. Interestingly, CKD is associated with gut barrier dysfunction, an increase in uremic toxins [101], elevated renal sympathetic activity [111], lower group B vitamin levels [112-114] and NO [115], and a reduction in vagal activity [116], which may stem from the gut dysbiosis found in patients with CKD. Therefore, we can suggest that a healthy gut microbiota can protect from CKD, whereas gut dysbiosis takes part in the development and progression of CKD through a number of pathways that manipulate host inflammatory activity.

Another pathway through which the gut microbiota can affect kidney function is the metabolic/endocrine interaction of the gut with the kidney. The gut microbiota acts like an endocrine organ by producing several neurotransmitters and affects intestinal endocrine activity. Species from Lactobacillaceae, Prevotellaceae, and Bifidobacteriaceae synthesize the neurotransmitters GABA and Ach [107, 110] and promote intestinal production of the incretins GLP-1, GLP-2, and PYY [76-79]. These neurotransmitters and hormones modulate renal function; for example, GABA can induce natriuresis [117] and suppress renal sympathetic nerve activity [117], Ach increases the glomerular filtration rate (GFR) by promoting renal vasodilatation [118], and GLP-1 increases the GFR, diuresis, and natriuresis while reducing proximal tubular sodium reabsorption and the angiotensin II (ANG II) level [119, 120]. PYY has controversial effects on renal function; it can reduce renal blood flow or increase diuresis/natriuresis and suppress plasma renin activity depending on the type of renal YY receptor it induces [121]. Additionally, by acting like hormones, the metabolic end products of these species, such as SCFAs and NO [16, 71, 73], can alter renal function. Activation of the renal SCFA receptor Olfr78 increases blood pressure in the physiological range by renin secretion, but this effect is counterbalanced or may even be reversed by the vasodilatory effect of the induction of the other SCFA receptors Gpr41 and Gpr43 [122-124]. Additionally, NO prevents ANG II and NE-dependent renal vasoconstriction [125]. In contrast, serotonin, which is produced by species from both Lactobacillaceae [126] and Bacteroidiaceae [127], induces renin release [128] and renal vasoconstriction via several different mechanisms [129-131]. Considering the "endocrine" activities of the gut microbiota on the kidneys, clearly the species that are reduced in the gut microbiota of CKD patients can actually provide renoprotection through reducing renin- angiotensin-aldosterone system activity [132] and favoring lower blood pressure [133] by reducing renin-angiotensin-aldosterone and renal sympathetic activity while increasing renal perfusion, diuresis, and natriuresis. Thus gut dysbiosis can be considered a reason for CKD progression via disruption of endocrine gut-kidney interactions.

Furthermore, the gut microbiota can interact with the kidneys via the ANS. A number of bacteria can modulate the functioning of the ANS. For example, some species from Lactobacillaceae can induce vagal activity $[90,93]$ and reduce renal sympathetic activity [90]. In addition to their analgesic and anxiolytic effects, some Lactobacilli and Bifidobacteria [91-96] can indirectly decrease the sympathetic tone of the host since both pain [134, 135] and anxiety [136] elevate sympathetic activity. Conversely, SCFAs have been found to have sympathoexcitatory effects [98], implying that all species that produce SCFAs, including Lactobacillaceae, Bifidobacteriaceae, and Prevotellaceae, have the potential to increase sympathetic activity. However, given that SCFAs can reduce blood pressure at the level of receptors [123], the possibility of a rise in sympathoexcitation-related blood pressure due to SCFA-producing bacteria is unlikely. The inflammatory conditions in the intestines can alter colonic sympathetic activity; for instance, ulcerative colitis increases sympathetic induction, whereas Crohn's disease causes a decrease in sympathetic activity by damaging the sympathetic fibers [137]. Taking into account that inflammation in ulcerative colitis remains superficial and the reduced sympathetic activity in Crohn's disease is probably due to injury to the sympathetic nerves, we can deduce that mucosal inflammation can cause sympathoexcitation. Furthermore, considering that Proteobacteriaceae can predispose the gut mucosa to inflammation [32, 35], these species may cause sympathoexcitation. Therefore, all things considered, gut dysbiosis in CKD patients may disturb the balance of ANS function in favor of SNS activity, which is an important contributor to progression of CKD [138].

Lastly, deterioration of renal function deepens derangement in the gut microbiota and mucosal integrity. Some purported metabolic mechanisms for this condition are expansion of uremic toxin-producing species with contraction of carbohydrate-fermenting SCFA-producing species for increased uremic toxin conservation and damage to the gut mucosa due to retention of uremic toxins, metabolic acidosis, fluid retention, and resulting intestinal congestion [25]. In addition, the increase in the urea level and its diffusion into the intestinal tract play important roles in alteration of the microbiome by mediating expansion of urease-possessing bacterial species [24]. Hydrolysis of urea in the gut lumen by these bacteria results in formation of ammonia and ammonium hydroxide, which disrupt the 


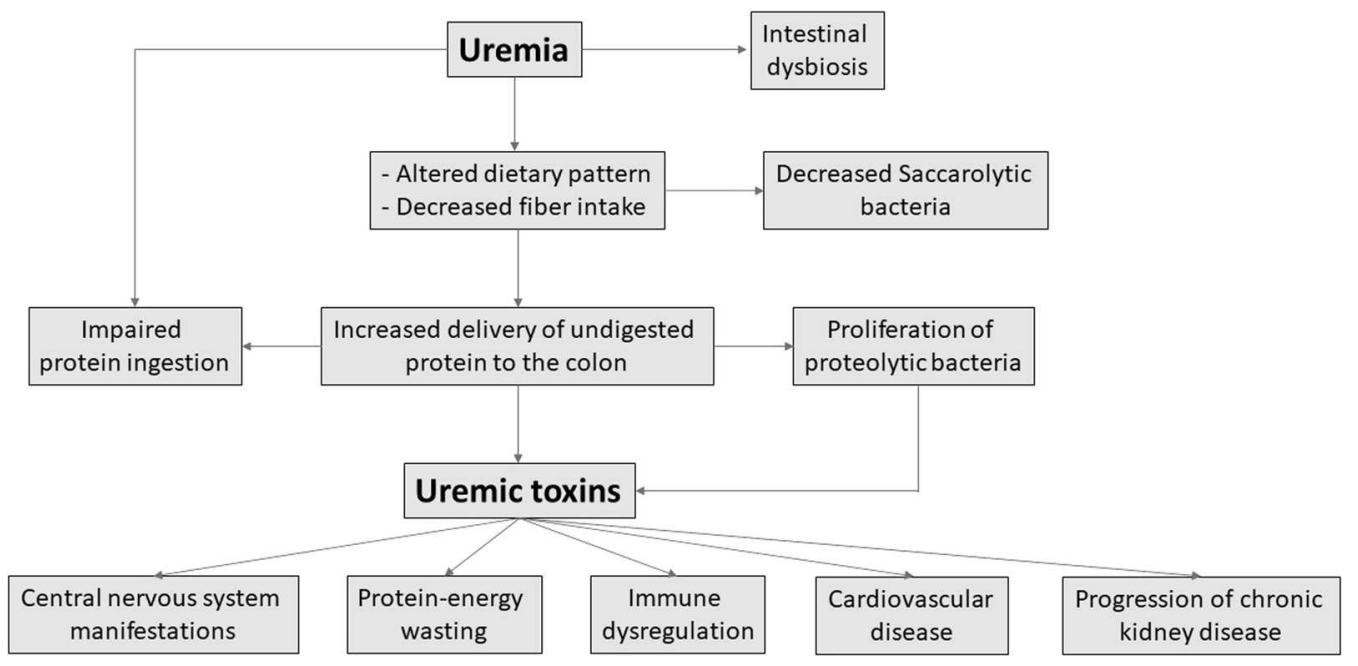

Fig. 2 Role of chronic kidney disease in the intestinal microbiota and its systemic effects

epithelial barrier by dissociating the sulfhydryl bonds in the tight junction and facilitate the entry of endotoxin and other noxious luminal contents into the intestinal wall, thereby causing local and systemic inflammation [139]. Moreover, the hormonal activity of the kidneys is changed in CKD patients, including an increase in the RAS activity [140] and reductions in the angiotensin-converting enzyme 2 [141], erythropoietin [142], and active vitamin D levels [143]. Importantly, these hormones have an effect on the gut microbiota and gut barrier function. ANG II can both damage the gut barrier [144] and cause dysbiosis with the reduction in butyrate-producing bacteria and the Bacteroidetes population due to hypertension [145], whereas angiotensin-converting enzyme 2 protects against intestinal inflammation [146]. Additionally, erythropoietin protects intestinal barrier function [147], and vitamin D provides a more immune-tolerant environment in the gut mucosa [148], further protecting the intestinal mucosal barrier from inflammatory destruction. Considering the alterations in renal hormone levels and the effects of these hormones on gut barrier function and the microbiota, CKD apparently worsens gut dysbiosis and mucosal damage not only at the metabolic level but also at the endocrine level (Fig. 2).

\section{Gut-heart crosstalk and inflammation in the development of CVD}

One important consequence of deranged crosstalk between the cardiovascular system and other organs is CVD. As an important modulator of gut-cardiovascular crosstalk, the gut microbiota is engaged in a bidirectional relationship with the cardiovascular system [149, 150]. Compared to that of healthy cases, the gut microbiota of patients with atherosclerosis has more species from genus Collinsella and fewer from genera Bacterioides, Roseburia, and
Eubacterium [151]. Additionally, the abundance of Lachnospiraceae and Erysipelotrichaceae in the gut flora is positively correlated with the total cholesterol and lowdensity lipoprotein (LDL)-cholesterol levels, and species from Proteobacteria colonize atherosclerotic plaques [152]. Gut dysbiosis is also evident in cases of hypertension and heart failure. In hypertension, an increased Firmicutes/ Bacteroidetes ratio reduced SCFA-producing bacteria, such as Bifidobacterium, Bacterioidetes, and Roseburia, and increased Prevotella, Klebsiella (from Proteobacteriaceae) and the lactate-producing Streptococcus and Turicibacter (from Erysipelotrichaceae) are found in the gut microbiota $[28,153]$. In patients with heart failure, species from genera Eubacterium and Dorea (from Clostridiaceae) are significantly reduced compared to that of the microbiota of the healthy controls [154]. Changes in the gut microbiota can affect cardiovascular health; in fact, transplantation of cecal contents from stroke-prone SHRs to normotensive rats resulted in blood pressure elevation of the normotensive rats [155]. The gut microbiota can affect cardiovascular function principally through inflammatory, metabolic/ endocrine, and neurologic pathways [156]. In turn, deterioration of cardiovascular function worsens gut barrier dysfunction and dysbiosis [150], creating a vicious cycle resulting in aggravation of CVD.

CVD is closely associated with chronic systemic inflammation [157], and the gut microbiota can affect the course of CVD development through its effects on inflammatory processes [158]. The gut microbiota can alter the host's tendency for inflammation through direct effects on gut barrier function [29]; interactions with Th cells [39]; and metabolic, endocrine, and neurologic activities [156]. In fact, gut barrier dysfunction can promote CVD development [159]. Bacteria supporting a more immunotolerant environment, such as Bacterioides [38] and Clostridia [39], 
are decreased in patients with hypertension and heart failure [153, 154]. Additionally, lactate, which is a pro-inflammatory metabolite [160] associated with hypertension [161], is produced by species such as Streptococcus and Turicibacter, which are enriched in the gut flora in hypertension cases [28]. These issues are highly important because hypertension is an autoimmune and inflammatory disease [162].

Other pro-inflammatory metabolites contributing to the development of CVD include the uremic toxins [41-45, 163, 164], which are produced by species such as Lachnospiraceae, Prevotella [165], Proteobacteria [68, 70], and Erysipelotrichaceae [166]. Interestingly, these bacteria are also increased in the gut microbiota of patients with atherosclerosis and hypertension [152, 153]. However, CVD is associated with loss of some beneficial bacteria, such as Bacterioides, Bifidobacterium, Roseburia, and Eubacterium [28, 151, 153, 154], which are known to primarily produce SCFAs [72-74], vitamin K [80], vitamin B complex [81], and GABA [110], which are mediators with antiinflammatory properties $[17,46,51-54,60,61]$. Since SCFAs also promote the production of anti-inflammatory gut hormones [57-59, 76-78], a decrease in SCFAproducing bacteria leads to a loss of "the endocrine protection method" from inflammation. Overall, by increasing the tendency of the host toward inflammation, gut dysbiosis can promote sympathetic activity since pro-inflammatory cytokines can induce SNS centrally [167]. In turn, SNS activity increases the blood pressure and has mostly proinflammatory properties [99], which can worsen CVD in general [157].

The metabolic end products and the effects of the gut microbiota on gut endocrine activity can influence the process of CVD development. Acting like an endocrine organ, the gut microbiota produces several neurotransmitters and metabolites that affect cardiovascular health. For example, Bifidobacteria, which are reduced in hypertension cases [153], produce GABA, which centrally prevents hypertension via its control over the SNS [168]. The loss of SCFAproducing bacteria in the gut microbiota can cause CVD by abolishing the antiatherogenic [169] and antihypertensive effects of the SCFAs [123]. On the other hand, species from Proteobacteria produce serotonin, NE, and DA [170], which are neurotransmitters with pro-hypertensive and pro-atherogenic properties [171-173], with the exception of DA [174-176]. Furthermore, the gut microbiota controls the endocrine activities of the intestine; for example, SCFAproducing bacteria, which are reduced in CVD cases [28, 151, 153, 154], promote secretion of incretins with cardioprotective, antiatherogenic, and antihypertensive properties [177-180], except for PYY [181, 182]. Therefore, the gut dysbiosis seen in CVD cases gives rise to an endocrine environment favoring CVD development.
Another pathway through which the gut microbiota affects cardiovascular health is modulation of the SNS. For example, Bifidobacteria can suppress SNS activity via the central effects of GABA, thereby protecting from hypertension [168]. Consistently, the gut microbiota contains less-than-normal Bifidobacteria in hypertension patients [153]. Moreover, gut mucosal inflammation deteriorates the mucosal barrier function, which can result in translocation of bacteria and bacterial products into the bloodstream and induction of pro-inflammatory cytokine secretion [159]. Since pro-inflammatory cytokines can stimulate the SNS centrally [167], we can hypothesize that any type of gut dysbiosis that compromises gut barrier function can increase the sympathetic tone of the host. Considering that sympathetic hyperactivity causes hypertension and other CVDs [183], the reason underlying CVD development in people with gut dysbiosis seen in cases of CVD may be partially due to sustained SNS activation by the dysbiotic gut microbiota.

The role of advanced glycation end products (AGEs) in CKD and CVD and their relationships with the gut microbiota also warrant mention. AGEs are a heterogeneous group of molecules, such as sugars, lipids, and nucleic acids, which are formed by nonenzymatic glycation reactions through a complex sequence of reactions referred to as Maillard reactions [184]. AGEs bind to cell surface receptors, such as AGER1 or, most importantly, to the receptor for AGEs (RAGE) [185].

The RAGE-AGE pathway is related to inflammation, oxidative stress, and endothelial dysfunction, which are all related to CKD and CVD [184, 186]. Vlassara et al. established for the first time that chronic intravenous injection of AGEs in healthy rats induced characteristic histological changes (glomerulosclerosis, mesangial matrix expansion, and basement membrane thickening) and albuminuria [187].

In addition, circulating AGE levels are independently associated with new or worsening nephropathy in type 2 diabetes (T2D) patients [188]. A direct role of AGEs in the development of cardiac dysfunction has been shown in animals [189]. However, some indirect arguments suggest a link. Abundant microvascular AGE deposition has also been observed in patients with diabetic cardiomyopathy [190] as well as within cardiomyocytes in epicardial biopsies from the hearts of patients undergoing transplantation [191]. This evidence strongly supports a role of AGEs as a risk factor for CKD and CVD.

In addition, recent evidence suggests that the gut microbiota and AGEs have a reciprocal relationship. Kinetic studies have estimated that $10-30 \%$ of consumed dietary AGEs (dAGEs) are absorbed in the upper intestine and enter the circulation [192]. The remaining AGEs escape digestion and reach the large bowel, where they undergo 
anaerobic fermentation and may mutually modulate gut microbiota growth [193].

In vitro studies have indicated that Maillard reaction products may affect bacterial growth [194] and the gut microbiota composition and that micro-organisms can degrade dAGEs [194]. AGEs may affect the gut microbiota through negative selection (direct toxic effects) or positive selection (favoring overgrowth of bacterial species that can utilize AGEs as an energy source) [195]. In a recent trial, Yacoup et al. evaluated the effect of restricting habitually high dietary AGE consumption on the gut microbiota in a group of ESRD patients on maintenance peritoneal dialysis (PD) and hypothesized that dAGE restriction affected the diversity of the bacterial gut microbiota in patients with ESRD receiving maintenance PD. These authors showed that dietary intervention resulted in an increase in the Firmicutes abundance and a decrease in Verrucomicrobia [195].

Another study demonstrated the protective effects of rosmarinic acid (RA) and carnosic acid (CA) against streptozotocin-induced oxidation, glycation, inflammation, and microbiota imbalance in diabetic rats with prebiotic effects. Compared with those of the model rats, CA administration increased the ratios of Actinobacteria, Bacteroidetes, Proteobacteria, and Verrucomicrobia, whereas RA administration increased the ratios of Actinobacteria, Proteobacteria, and Verrucomicrobia. Interestingly, Fusobacteria was only detected in the feces of the diabetic rats administered RA and CA [196].

Another study showed that mice fed a typical Western diet (WD) demonstrated gut dysbiosis, mainly including reductions in Bifidobacterium species, increased arterial stiffness, endothelial dysfunction, and increases in circulating LPS-binding protein (LBP), interleukin (IL)-6, and phosphorylated nuclear factor- $\kappa B$. Antibiotic treatment successfully abrogated the gut microbiota and reversed the WDinduced arterial stiffness and endothelial dysfunction. These improvements were accompanied by significant reductions in the LBP, IL-6, nuclear factor-kB, and AGEs [197].

Mastrocola et al. showed that a fructose diet, especially in solid form, resulted in gut dysbiosis, with increased colonization by Bacteroides, Lactobacillus, Lachnospiraceae, and Dorea and the accumulation of the AGEs $N$ (epsilon)-(carboxymethyl)lysine and $N$ (epsilon)-(carboxyethyl)lysine in the intestinal mucosa as revealed by immunofluorescence [198]. Qu et al. demonstrated that Sprague-Dawley rats exposed to a high-AGE diet showed richness of the microbiota, especially saccharolytic bacteria, such as Ruminococcaceae and Alloprevotella, although some putatively harmful bacteria (Desulfovibrio and Bacteroides) were also increased [199].

Finally, deteriorations in cardiovascular function further aggravate gut barrier dysfunction and dysbiosis [150]. As observed in congestive heart failure patients, gut mucosal permeability is increased and bacteria are more adherent to the gut mucosa, probably due to mucosal ischemia/hypoxia/ edema [150]. Additionally, congestive heart failure leads to an increase in sympathetic activity, which can impair gut barrier function by causing mucosal ischemia due to reduced splanchnic blood flow [150] and via its proinflammatory effects on the gut mucosa [99]. In summary, development of cardiovascular impairment contributes to a vicious cycle, leading to progression of CVD by exacerbating gut dysbiosis and barrier dysfunction.

\section{Cardiovascular-renal crosstalk, cardiorenal syndromes, and the gut microbiota}

The cardiovascular system and the kidneys are intimately related to each other. Thus impairment in the functioning of either system deteriorates the functioning of the other, giving rise to cardiorenal syndromes [200, 201]. Basically, CKD can distort cardiovascular functions through uremic toxin retention, abnormalities in renal calcium/phosphate handling, overactivation of the SNS and RAS, anemia, and increased oxidative stress, resulting in the development of chronic renocardiac syndrome [200] and fluid overload. Moreover, chronic heart failure can compromise renal function via chronic renal hypoperfusion/congestion and consequent RAS activity, SNS activation, systemic inflammation, and RAS activation, giving rise to cardiorenal syndrome. In addition to this "ping-pong relationship" between the cardiovascular and renal systems, the gut microbiota can affect the development of chronic renocardiac syndrome. For example, the uremic toxins produced by the gut microbiota can aggravate chronic renocardiac syndrome via deleterious effects on both cardiovascular and renal health mostly through inflammatory pathways [202]. In fact, although the alterations detected in the gut microbiota of patients with CKD and CVD were not exactly the same, generally an increase in the uremic toxinproducing species, a decrease in SCFA-producing bacteria and compromise of the gut barrier function were evident [28, 101-104, 152, 159, 203].

To be more succinct, we will discuss some specific mechanisms and mediators of gut-cardiovascular and kidney crosstalk. Renal dysfunction causes not only metabolic derangements but also systemic inflammation, as indicated by elevation of C-reactive protein, pentraxin-3, proinflammatory cytokine sTWEAK (tumor necrosis factorlike weak inducer of apoptosis), sTRAIL (tumor necrosis factor-related apoptosis-inducing ligand), S100A12 (extracellular newly identified RAGE-binding protein), mannosebinding lectin, and activated complement levels [203, 204]. LPS-induced monocyte/macrophage activation and systemic inflammation can explain the persistent systemic inflammation in CKD/ESRD [203]. Moreover, the intestinal 
microbiota is increasingly recognized as a modifier of the host immune system, especially polarization of $\mathrm{T}$ cell subsets and natural killer T cells [205, 206]. Edematous heart failure patients were shown to have high serum endotoxin and cytokine levels that declined upon diuretic therapy [207]. Wang et al. showed that experimental uremia in rats increased bacterial translocation from the gut into the mesenteric lymph nodes, liver, and spleen, which was associated with higher serum IL-6 and C-reactive protein levels [208]. Thus CKD-related dysbiosis and changes in the intestinal barrier may favor increased translocation of living bacteria or bacterial products from the intestinal lumen into the circulation, which is a process that can account for the persistent systemic inflammation in CKD patients and is also associated with CVD.

Increases in LPS may also be related to atherosclerosis via other mechanisms. For example, the LPS receptor Tolllike receptor 4 (TLR4) is a mediator of atherosclerosis, which may imply that increased LPS/TLR4 signaling can be a driving factor of accelerated atherogenesis in CKD/ESRD patients [209]. In addition, neutralizing the bacteria-derived uremic toxin IS inside the gut delays CKD and CVD progression in uremic rats [210].

Another mediator of gut-kidney and cardiovascular crosstalk may be TMAO, which is a gut microbiotagenerated metabolite that is thought to play a role in endothelial dysfunction, inflammation, and CVD. Circulating TMAO is elevated in CKD. In a 5/6 nephrectomy model, $\mathrm{Li}$ et al. showed that the TMAO levels were markedly elevated in CKD-vehicle rats compared with those of sham-vehicle rats. However, rats treated with $1.0 \%$ 3,3dimethyl-1-butanol (DMB, an inhibitor of trimethylamine (TMA) formation) for 8 weeks had reduced TMAO levels. Acetylcholine-induced endothelium-dependent vasodilation was impaired in CKD-vehicle rats compared with that of sham-vehicle rats, as indicated by the reduced maximal relaxation (Emax) and decreased area under the curve (AUC). The Emax and AUC were both normalized in the CKD-DMB rats. Molecular studies revealed that endothelial NO synthase (eNOS) activity was decreased and superoxide production and pro-inflammatory cytokine expression were increased in the aortas of CKD-vehicle rats compared with those of the sham-vehicle rats. Notably, the abnormalities in the above molecular parameters were completely restored in the CKD-DMB rats. These results suggest that CKD elevates circulating TMAO levels, which may reduce eNOSderived NO production by increasing vascular oxidative stress and inflammation, thereby contributing to CKDassociated endothelial dysfunction and CVD [211].

Some other mediators and toxins may operate in this crosstalk. Among these toxins are IS, p-CS, and indole-3acetic acid (IAA), which originate from bacterial protein fermentation in the large intestine. These toxins derived from tryptophan are ligands of the aryl hydrocarbon receptor, whose activation is involved in atherogenesis, vascular inflammation, and oxidative stress [212]. Recent studies have reported that these toxins induce proinflammatory responses and are reliable markers of CVD and mortality in CKD patients [213]. Borges et al. studied protein-bound uremic toxins from the gut microbiota and inflammatory markers in CKD. The total levels of uremic toxins (IS, p-CS, and IAA) were assessed by highperformance liquid chromatography with fluorescence detection. The C-reactive protein, IL-6, monocyte chemoattractant protein-1 (MCP-1), and calprotectin plasma levels were determined by immunometric assays. Hemodialysis (HD) patients presented higher inflammatory markers and uremic toxin levels than the nondialysis patients. The IL-6 levels were positively correlated with IS, p-CS, and IAA. A positive correlation was also observed for the MCP-1 levels with IS, $\mathrm{p}-\mathrm{CS}(r=0.48 ; P<0.001)$, and IAA [212].

Therefore, we can sensibly consider CKD and CVD as the two interlinked causes and consequences of gut barrier dysfunction and dysbiosis that form an ominous gut-kidney-heart/vessel triangle, resulting in cardiorenal syndromes with gut dysbiosis and compromised gut barrier dysfunction.

\section{Gut microbiota as a new target for the prevention and treatment of CKD and CVD}

Current understanding of the role of the gut microbiota in cardiovascular and renal health has led to the development of new strategies to protect the balance of the gut microbiota and prevent dysbiosis. Indeed, metabolic phenotyping of biological systems has proven its application in characterizing metabolites and providing novel insights into gene-environmental-gut microbiome interactions in relation to a disease state [214]. These efforts can be grouped into four categories: probiotic use, diet modification, medications, and exercise.

The gut microbiota can be reconstructed with the use of beneficial bacteria. Probiotics are live bacteria with moderating properties on inflammation [215], such as Lactobacilli, Bifidobacteria, and Streptococci [216]. In fact, treatment with Lactobacillus species resulted in a reduction of the atherosclerotic burden in ApoE 2/2 mice [217] and decreased the serum levels of endotoxins and proinflammatory cytokines while increasing those of antiinflammatory cytokines, thereby preserving residual renal function in PD patients [218]. Additionally, Methanomassiliicoccus luminyensis $\mathrm{B} 10$, which is a strain of archaea, has been shown to degrade TMAO and has been suggested for utilization as a probiotic [219]. Therefore, engineering the gut microbiota via beneficial 
microorganisms can be a modality to prevent or even treat CVD and CKD.

Our diet feeds not only us but also the bacteria in our gut flora. For example, protein and animal fat-rich diets favor the growth of Bacteroides species, whereas carbohydrate-rich diets expand Prevotella species in the gut microbiome [220]. Therefore, modifications of dietary habits can support a healthier gut microbiota. For example, a fruit/vegetable-rich diet with flavonoid intake suppresses growth of pathogenic Clostridia [221], and meeting the dietary protein need from plants instead of animal-based foods can reduce the CVD risk possibly by evading the production of harmful metabolites, such as TMAO, from metabolism of choline and L-carnitine, which are abundant in animal-based foods [222]. A well-known strategy to modify the gut microbiota with diet is the use of prebiotics, which are indigestible food ingredients that support the growth of beneficial bacteria, such as Lactobacilli and Bifidobacteria species, while suppressing the growth of others, such as species from genera Enterobacteria, Clostridia, and Bacteroides [223]. In fact, high dietary fiber intake reduces the risk of inflammation and mortality in CKD patients [224]. In addition, consumption of an amylose-enriched diet has been shown to attenuate oxidative stress and inflammation, retard CKD progression, and markedly improve gut microbial dysbiosis in a rat model of CKD [225]. Moreover, beneficial bacteria in the gut microbiota can be supported by dietary supplementation of polyphenols [226], vitamin D [227], zinc [228], and iron [229], and some plant-derived essential oils [230] and fish oil [231] can suppress the growth of pathogenic species. Dietary L-arginine supplementation also strengthens gut mucosal immune barrier function [232]. Therefore, a balanced diet rich in plant-derived foods can promote a healthier gut flora.

Importantly, some medications can have favorable effects on the gut microbiota. First, oral hypoglycemic agents, such as metformin, can alter the gut microbiota in favor of beneficial species, such as Akkermansia muciniphila, which can thicken the mucus barrier [233], and Eubacterium while suppressing group Firmicutes in general [234]. Additionally, use of liraglutide and saxagliptin has been reported to improve the Lactobacillaceae level in the gut flora [235]. Furthermore, lubipristone can restore the Lactobacillaceae and Prevotella composition of the gut microbiota of mice with renal failure, thereby reducing the plasma levels of uremic toxins [236]. Emodin, which is the main ingredient of the Chinese medicine rhubarb, reduces the serum uremic toxin levels by suppressing the growth of Clostridium species and other harmful species while promoting the expansion of beneficial bacteria, such as Lactobacillus species [237].
Alpha-glucosidase inhibitors are other antidiabetic drugs that delay the digestion of carbohydrates, such as disaccharides and starch, in the small intestine. Acarbose administration in hyperlipidemic or T2D patients was shown to increase Lactobacillus and Bifidobacterium [238] as well as other SCFA-producing bacteria, such as Faecalibacterium and Prevotella [238]. Additionally, animal studies have shown that GLP-1 receptor agonists and dipeptidyl peptidase 4 inhibitors can alter the gut microbiota [239]. However, human studies in this context are not available at present. We also did not find any study showing the influence of sodium glucose co-transporter 2 inhibitors or meglitinides on the gut microbiota, and information is very scarce regarding sulfonylureas and thiazolidinediones.

Apart from hypoglycemic agents, a variety of drugs are used for the prevention of CKD and CVD. Recent evidence suggests that these drugs may affect the microbiota. Kjan et al. investigated the effects of atorvastatin treatment on the gut microbiota. The authors performed 16S rDNA amplicon sequencing to evaluate the gut bacterial communities of 15 untreated hypercholesterolemic patients (HPs) and 27 atorvastatin-treated hypercholesterolemic patients (At-HPs) compared with those of 19 healthy subjects (HSs). In total, 18 different phyla were identified in the study groups. An increase in relative abundance of Proteobacteria was observed in the HP group compared with that of the At-HP and HS groups. The atherosclerosis-associated genus Collinsella was found at a relatively higher abundance in the HP group. Anti-inflammation-associated bacteria (Faecalibacterium prausnitzii, A. muciniphila, and genus Oscillospira) were found in greater abundances, and the proinflammatory species Desulfovibrio sp. was observed at a decreased abundance in the drug-treated HP group compared with that of the untreated HP group. The relative abundances of Bilophila wadsworthia and Bifidobacterium bifidum (bile acid-associated species) were decreased in the At-HP group. These data suggest that atorvastatin treatment of patients with hypercholesterolemia may selectively restore the relative abundance of several dominant and functionally important taxa that are disrupted in HPs [240]. Simvastatin was also shown to affect the gut microbial composition and boost Lactobacillus populations [241]. Additionally, the relationship between antilipemic drugs and the microbiota is bi-directional instead of unidirectional. Costabile et al. showed that Lactobacillus plantarum ECGC 13110402 resulted in a statistically significant reduction in LDL cholesterol, a significant reduction in total cholesterol, a significant decrease in triglycerides, and an increase in high-density lipoprotein cholesterol during a 6-12-week period [242].

Regarding antihypertensive drugs, no specific study has investigated the effect of drugs on the gut microbiota. In 
contrast, many studies have shown that probiotics may have antihypertensive effects [243].

These findings suggest that the gut microbiota can be modified by some medications. Therefore, an investigation of the effects of currently used medications on the gut microbiota is reasonable, and those with the greatest benefits on the gut microbiota may even be chosen as adjunct therapies for insufficient prebiotic/probiotic treatments.

Interestingly, not only diet and medications but also the physical activity level can alter the gut microbiota composition. There is mounting evidence that exercise supports the growth of beneficial species and enriches the diversity of the gut microbiota, thereby improving health [244]. Therefore, regular exercise keeps not only the body but also the gut microbiota fit.

The role of the gut microbiota in the central nervous system (CNS; e.g., appetite and the reward system) is also worth mentioning. Energy homeostasis is tightly regulated by the CNS, which responds to nervous and circulating inputs to adapt food intake and energy expenditure. The rewarding and motivational aspects of food are tightly dependent on DA release in the mesocorticolimbic system. Accumulating evidence indicates that manipulating the microbiota-gut-brain axis through prebiotic supplementation can have beneficial impacts of the host's appetite and body weight [245].

Indeed, microbial metabolites were suggested to affect host metabolism through a variety of pathways, one of which was affecting central appetite pathways integrating the host energy status [246]. Bacterial strains were also hypothesized to provide a potent therapeutic for neurological diseases by producing or altering neurochemicals and could most likely play a pivotal role in influencing appetite and energy metabolism via modulation of the CNS [247].

Various studies have shown that dietary prebiotics, such as the soluble fibers fructo-oligosaccharides, which represents selectively fermented compounds, promote changes in the activity and composition of the gut microbiota that are associated with reduced appetite [248]. A recent study showed that weight gain in anorexia nervosa was related to dysregulation of appetite and decreased gut microbial diversity [249].

Administration of Citrobacter rodentium to mice increased anxiety-like behaviors [93] and B. longum normalized anxiety-like behavior following nematode-induced gastrointestinal inflammation [92]. Clinical studies have also suggested that ingestion of probiotics may decrease anxiety and depression [250]. This evidence suggests that the gut microbiota affects higher CNS functions and behavior, but large clinical trials are needed to evaluate the efficacy of antibiotic as well as probiotic ("psychobiotic") therapies.
Lastly, other than the gut microbiota, its products, such as the uremic toxins and LPS, can be targeted to prevent the development and progression of CKD and CVD. For example, adsorption of uremic toxins by AST-120 [251], blocking metabolic pathways leading to the production of the uremic toxins TMAO and IS with TMA inhibitor [252] and inhibition of hepatic sulfation of indoxyl [253] are among the strategies being developed to reduce serum uremic toxin levels and attenuate consequent inflammation [254]. Additionally, sevelamer, which is a large cationic polymer phosphate binder, has been shown to adsorb and remove LPS in HD patients [251]. Therefore, investigation of the metabolism of toxins produced by bacteria and development of new methods to prevent the deleterious effects of bacterial metabolic waste products and endotoxins are important avenues for the prevention and treatment of $\mathrm{CKD}, \mathrm{CVD}$, and other chronic inflammatory diseases.

\section{Conclusion}

The intestines, cardiovascular system, and kidneys are intimately engaged with each other, and their crosstalk plays a decisive role in the development of two of the most common and important chronic diseases: CKD and CVD. The gut microbiota and its effects on the host inflammatory status are key components of this crosstalk. Therefore, deciphering the role of the gut microbiota in gut-cardiovascular system-kidney crosstalk will create novel opportunities for the prevention and treatment of many previously undertreated conditions, including CVD and CKD.

Author contributions All authors approved the final version of the manuscript.

Funding The authors declare that they have no conflict of interest.

\section{References}

1. Sender R, Fuchs S, Milo R. Are we really vastly outnumbered? Revisiting the ratio of bacterial to host cells in humans. Cell. 2016;164:337-40.

2. Mahmoodpoor F, Rahbar Saadat Y, Barzegari A, Ardalan M, Zununi Vahed S. The impact of gut microbiota on kidney function and pathogenesis. Biomed Pharmacother. 2017;93:412-9.

3. Tang WH, Kitai T, Hazen SL. Gut microbiota in cardiovascular health and disease. Circ Res. 2017;120:1183-96.

4. Savage DC. Microbial ecology of the gastrointestinal tract. Annu Rev Microbiol. 1977;31:107-33.

5. Lozupone CA, Stombaugh JI, Gordon JI, Jansson JK, Knight R. Diversity, stability and resilience of the human gut microbiota. Nature. 2012;489:220-30. 
6. Hooper LV, Gordon JI. Commensal host-bacterial relationships in the gut. Science. 2001;292:1115-8.

7. Coakley M, Ross RP, Nordgren M, Fitzgerald G, Devery R, Stanton C. Conjugated linoleic acid biosynthesis by humanderived Bifidobacterium species. J Appl Microbiol. 2003;94: 138-45.

8. Metges CC. Contribution of microbial amino acids to amino acid homeostasis of the host. J Nutr. 2000;130:1857s-1864s.

9. Burkholder PR, McVeigh I. Synthesis of vitamins by intestinal bacteria. Proc Natl Acad Sci USA. 1942;28:285-9.

10. Fernandez F, Hill MJ. Proceedings: The production of vitamin K by human intestinal bacteria. J Med Microbiol. 1975;8:Pix.

11. Savage DC. Gastrointestinal microflora in mammalian nutrition. Annu Rev Nutr. 1986;6:155-78.

12. Malys MK, Campbell L, Malys N. Symbiotic and antibiotic interactions between gut commensal microbiota and host immune system. Medicinia (Kaunas). 2015;51:69-75.

13. Robijn S, Hoppe B, Vervaet BA, D'Haese PC, Verhulst A. Hyperoxaluria: a gut-kidney axis? Kidney Int. 2011;80:1146-58.

14. Liu H, Hu C, Zhang X, Jia W. Role of gut microbiota, bile acids and their cross-talk in the effects of bariatric surgery on obesity and type 2 diabetes. J Diabetes Investig. 2017;9:13-20.

15. Pluznick JL. Gut microbiota in renal physiology: focus on shortchain fatty acids and their receptors. Kidney Int. 2016;90: 1191-8.

16. Sobko T, Huang L, Midtvedt T, Norin E, Gustafsson LE, Norman $\mathrm{M}$, et al. Generation of NO by probiotic bacteria in the gastrointestinal tract. Free Radic Biol Med. 2006;41:985-91.

17. de Andrade JA, Gayer CR, Nogueira NP, Paes MC, Bastos VL, Neto Jda C, et al. The effect of thiamine deficiency on inflammation, oxidative stress and cellular migration in an experimental model of sepsis. J Inflamm (Lond). 2014;11:11.

18. Nudel BC, Fraile ER. [Selection of bacterial strains for the production of threonine]. Rev Argent Microbiol. 1984;16: 209-17.

19. Romano M. Gut microbiota as a trigger of accelerated directional adaptive evolution: acquisition of herbivory in the context of extracellular vesicles, microRNAs and inter-kingdom crosstalk. Front Microbiol. 2017;8:721.

20. Afsar B, Vaziri ND, Aslan G, Tarim K, Kanbay M. Gut hormones and gut microbiota: implications for kidney function and hypertension. J Am Soc Hypertens. 2016;10:954-61.

21. Lyte M. Probiotics function mechanistically as delivery vehicles for neuroactive compounds: microbial endocrinology in the design and use of probiotics. Bioessays. 2011;33:574-81.

22. Wang HX, Wang YP. Gut microbiota-brain axis. Chin Med J. 2016;129:2373-80.

23. Muccioli GG, Naslain D, Backhed F, Reigstad CS, Lambert DM, Delzenne NM, et al. The endocannabinoid system links gut microbiota to adipogenesis. Mol Syst Biol. 2010;6:392.

24. Vaziri ND, Wong J, Pahl M, Piceno YM, Yuan J, DeSantis TZ, et al. Chronic kidney disease alters intestinal microbial flora. Kidney Int. 2013;83:308-15.

25. Khoury T, Tzukert K, Abel R, Abu Rmeileh A, Levi R, Ilan Y. The gut-kidney axis in chronic renal failure: a new potential target for therapy. Hemodial Int. 2016;21:323-34.

26. Nagatomo Y, Tang WH. Intersections between microbiome and heart failure: revisiting the gut hypothesis. J Card Fail. 2015;21:973-80.

27. Kanbay M, Onal EM, Afsar B, Dagel T, Yerlikaya A, Covic A, et al. The crosstalk of gut microbiota and chronic kidney disease: role of inflammation, proteinuria, hypertension, and diabetes mellitus. Int Urol Nephrol. 2018;50:1453-66.

28. Yang T, Santisteban MM, Rodriguez V, Li E, Ahmari N, Carvajal JM, et al. Gut dysbiosis is linked to hypertension. Hypertension. 2015;65:1331-40.
29. Xu KY, Xia GH, Lu JQ, Chen MX, Zhen X, Wang S, et al. Impaired renal function and dysbiosis of gut microbiota contribute to increased trimethylamine-N-oxide in chronic kidney disease patients. Sci Rep. 2017;7:1445.

30. Rossi M, Klein K, Johnson DW, Campbell KL. Pre-, pro-, and synbiotics: do they have a role in reducing uremic toxins? A systematic review and meta-analysis. Int J Nephrol. 2012;2012: 673631.

31. Vanholder R, Schepers E, Pletinck A, Nagler EV, Glorieux G. The uremic toxicity of indoxyl sulfate and p-cresyl sulfate: a systematic review. J Am Soc Nephrol. 2014;25:1897-907.

32. Jakobsson HE, Rodriguez-Pineiro AM, Schutte A, Ermund A, Boysen P, Bemark M, et al. The composition of the gut microbiota shapes the colon mucus barrier. EMBO Rep. 2015;16: 164-77.

33. Ulluwishewa D, Anderson RC, McNabb WC, Moughan PJ, Wells JM, Roy NC. Regulation of tight junction permeability by intestinal bacteria and dietary components. J Nutr. 2011;141: 769-76.

34. Lee J, Mo JH, Katakura K, Alkalay I, Rucker AN, Liu YT, et al. Maintenance of colonic homeostasis by distinctive apical TLR9 signalling in intestinal epithelial cells. Nat Cell Biol. 2006;8:1327-36.

35. Omenetti S, Pizarro TT. The Treg/Th17 axis: a dynamic balance regulated by the gut microbiome. Front Immunol. 2015;6:639.

36. Ohland CL, Macnaughton WK. Probiotic bacteria and intestinal epithelial barrier function. Am J Physiol Gastrointest Liver Physiol. 2010;298:G807-819.

37. Watson AJ, Duckworth CA. Gut microbiota control gut permeability through GLP-2. Gastroenterology. 2010;138:779-81.

38. Round JL, Lee SM, Li J, Tran G, Jabri B, Chatila TA, et al. The Toll-like receptor 2 pathway establishes colonization by a commensal of the human microbiota. Science. 2011;332: 974-7.

39. Geuking MB, Cahenzli J, Lawson MA, Ng DC, Slack E, Hapfelmeier $\mathrm{S}$, et al. Intestinal bacterial colonization induces mutualistic regulatory $\mathrm{T}$ cell responses. Immunity. 2011;34: 794-806.

40. Brandl K, Schnabl B. Is intestinal inflammation linking dysbiosis to gut barrier dysfunction during liver disease? Expert Rev Gastroenterol Hepatol. 2015;9:1069-76.

41. Poveda J, Sanchez-Nino MD, Glorieux G, Sanz AB, Egido J, Vanholder R, et al. p-cresyl sulphate has pro-inflammatory and cytotoxic actions on human proximal tubular epithelial cells. Nephrol Dial Transplant. 2014;29:56-64.

42. Brunet P, Gondouin B, Duval-Sabatier A, Dou L, Cerini C, Dignat-George F, et al. Does uremia cause vascular dysfunction? Kidney Blood Press Res. 2011;34:284-90.

43. Ito S, Osaka M, Higuchi Y, Nishijima F, Ishii H, Yoshida M. Indoxyl sulfate induces leukocyte-endothelial interactions through up-regulation of E-selectin. J Biol Chem. 2010;285: 38869-75.

44. Shimizu H, Bolati D, Adijiang A, Muteliefu G, Enomoto A, Nishijima F, et al. NF-kappaB plays an important role in indoxyl sulfate-induced cellular senescence, fibrotic gene expression, and inhibition of proliferation in proximal tubular cells. Am J Physiol Cell Physiol. 2011;301:C1201-1212.

45. Seldin MM, Meng Y, Qi H, Zhu W, Wang Z, Hazen SL, et al. Trimethylamine N-oxide promotes vascular inflammation through signaling of mitogen-activated protein kinase and nuclear factor-kappaB. J Am Heart Assoc. 2016;5:e002767.

46. Saemann MD, Bohmig GA, Osterreicher $\mathrm{CH}$, Burtscher $\mathrm{H}$, Parolini O, Diakos C, et al. Anti-inflammatory effects of sodium butyrate on human monocytes: potent inhibition of IL-12 and up-regulation of IL-10 production. FASEB J. 2000;14: $2380-2$. 
47. Laroux FS, Pavlick KP, Hines IN, Kawachi S, Harada H, Bharwani $\mathrm{S}$, et al. Role of nitric oxide in inflammation. Acta Physiol Scand. 2001;173:113-8.

48. Knauf F, Asplin JR, Granja I, Schmidt IM, Moeckel GW, David $\mathrm{RJ}$, et al. NALP3-mediated inflammation is a principal cause of progressive renal failure in oxalate nephropathy. Kidney Int. 2013;84:895-901.

49. Hatch M. Gut microbiota and oxalate homeostasis. Ann Transl Med. 2017;5:36.

50. Zhu C, Fuchs CD, Halilbasic E, Trauner M. Bile acids in regulation of inflammation and immunity: friend or foe? Clin Exp Rheumatol. 2016;34:25-31.

51. Ohsaki Y, Shirakawa H, Hiwatashi K, Furukawa Y, Mizutani T, Komai M. Vitamin K suppresses lipopolysaccharide-induced inflammation in the rat. Biosci Biotechnol Biochem. 2006;70: 926-32.

52. Granados-Soto V, Teran-Rosales F, Rocha-Gonzalez HI, ReyesGarcia G, Medina-Santillan R, Rodriguez-Silverio J, et al. Riboflavin reduces hyperalgesia and inflammation but not tactile allodynia in the rat. Eur J Pharmacol. 2004;492:35-40.

53. Zhang P, Tsuchiya K, Kinoshita T, Kushiyama H, Suidasari S, Hatakeyama M, et al. Vitamin B6 prevents IL-1beta protein production by inhibiting NLRP3 inflammasome activation. J Biol Chem. 2016;291:24517-27.

54. Guest J, Bilgin A, Hokin B, Mori TA, Croft KD, Grant R. Novel relationships between B12, folate and markers of inflammation, oxidative stress and $\mathrm{NAD}(\mathrm{H})$ levels, systemically and in the CNS of a healthy human cohort. Nutr Neurosci. 2015;18:355-64.

55. Osowska S, De Bandt JP, Chaib S, Neveux N, Berard MP, Cynober L. Efficiency of a cysteine-taurine-threonine-serine supplemented parenteral nutrition in an experimental model of acute inflammation. Intensive Care Med. 2003;29:1798-801.

56. Filip AT, Balacescu O, Marian C, Anghel A. Microbiota small RNAs in inflammatory bowel disease. J Gastrointest liver Dis. 2016;25:509-16.

57. Lee YS, Park MS, Choung JS, Kim SS, Oh HH, Choi CS, et al. Glucagon-like peptide-1 inhibits adipose tissue macrophage infiltration and inflammation in an obese mouse model of diabetes. Diabetologia. 2012;55:2456-68.

58. Cani PD, Possemiers S, Van de Wiele T, Guiot Y, Everard A, Rottier $\mathrm{O}$, et al. Changes in gut microbiota control inflammation in obese mice through a mechanism involving GLP-2-driven improvement of gut permeability. Gut. 2009;58:1091-103.

59. Vona-Davis L, McFadden DW. PYY and the pancreas: inhibition of tumor growth and inflammation. Peptides. 2007;28:334-8.

60. Duthey B, Hubner A, Diehl S, Boehncke S, Pfeffer J, Boehncke WH. Anti-inflammatory effects of the GABA(B) receptor agonist baclofen in allergic contact dermatitis. Exp Dermatol. 2010;19: 661-6.

61. Reyes-Garcia MG, Hernandez-Hernandez F, Hernandez-Tellez B, Garcia-Tamayo F. GABA (A) receptor subunits RNA expression in mice peritoneal macrophages modulate their IL-6/ IL-12 production. J Neuroimmunol. 2007;188:64-68.

62. Shajib MS, Khan WI. The role of serotonin and its receptors in activation of immune responses and inflammation. Acta Physiol (Oxf). 2015;213:561-74.

63. Spengler RN, Chensue SW, Giacherio DA, Blenk N, Kunkel SL. Endogenous norepinephrine regulates tumor necrosis factoralpha production from macrophages in vitro. J Immunol. 1994;152:3024-31.

64. Yan Y, Jiang W, Liu L, Wang X, Ding C, Tian Z, et al. Dopamine controls systemic inflammation through inhibition of NLRP3 inflammasome. Cell. 2015;160:62-73.

65. Baez-Pagan CA, Delgado-Velez M, Lasalde-Dominicci JA. Activation of the macrophage alpha7 nicotinic acetylcholine receptor and control of inflammation. J NeuroImmune Pharmacol. 2015;10:468-76.

66. Chobanyan-Jurgens K, Jordan J. Autonomic nervous system activity and inflammation: good ideas, good treatments, or both? Am J Physiol Heart Circ Physiol. 2015;309: H1999-2001.

67. Gabanyi I, Muller PA, Feighery L, Oliveira TY, Costa-Pinto FA, Mucida D. Neuro-immune interactions drive tissue programming in intestinal macrophages. Cell. 2016;164:378-91.

68. Fernandez-Prado R, Esteras R, Perez-Gomez MV, GraciaIguacel C, Gonzalez-Parra E, Sanz AB, et al. Nutrients turned into toxins: microbiota modulation of nutrient properties in chronic kidney disease. Nutrients 2017;9:E489.

69. Moraes C, Fouque D, Amaral AC, Mafra D. Trimethylamine Noxide from gut microbiota in chronic kidney disease patients: focus on diet. J Ren Nutr. 2015;25:459-65.

70. Romano KA, Vivas EI, Amador-Noguez D, Rey FE. Intestinal microbiota composition modulates choline bioavailability from diet and accumulation of the proatherogenic metabolite trimethylamine-N-oxide. mBio. 2015;6:e02481.

71. Wong J, Piceno YM, Desantis TZ, Pahl M, Andersen GL, Vaziri ND. Expansion of urease- and uricase-containing, indole- and pcresol-forming and contraction of short-chain fatty acidproducing intestinal microbiota in ESRD. Am $\mathrm{J}$ Nephrol. 2014;39:230-7.

72. Pogribna M, Freeman JP, Paine D, Boudreau MD. Effect of Aloe vera whole leaf extract on short chain fatty acids production by Bacteroides fragilis, Bifidobacterium infantis and Eubacterium limosum. Lett Appl Microbiol. 2008;46:575-80.

73. Barcenilla A, Pryde SE, Martin JC, Duncan SH, Stewart CS, Henderson $\mathrm{C}$, et al. Phylogenetic relationships of butyrateproducing bacteria from the human gut. Appl Environ Microbiol. 2000;66:1654-61.

74. Duncan SH, Hold GL, Barcenilla A, Stewart CS, Flint HJ. Roseburia intestinalis sp. nov., a novel saccharolytic, butyrateproducing bacterium from human faeces. Int J Syst Evol Microbiol. 2002;52:1615-20.

75. Tsukahara T, Koyama H, Okada M, Ushida K. Stimulation of butyrate production by gluconic acid in batch culture of pig cecal digesta and identification of butyrate-producing bacteria. J Nutr. 2002;132:2229-34.

76. Everard A, Cani PD. Gut microbiota and GLP-1. Rev Endocr Metab Disord. 2014;15:189-96.

77. Samuel BS, Shaito A, Motoike T, Rey FE, Backhed F, Manchester JK, et al. Effects of the gut microbiota on host adiposity are modulated by the short-chain fatty-acid binding $G$ protein-coupled receptor, Gpr41. Proc Natl Acad Sci USA. 2008;105:16767-72.

78. Simon MC, Strassburger K, Nowotny B, Kolb H, Nowotny P, Burkart $\mathrm{V}$, et al. Intake of Lactobacillus reuteri improves incretin and insulin secretion in glucose-tolerant humans: a proof of concept. Diabetes Care. 2015;38:1827-34.

79. Holzer P, Farzi A. Neuropeptides and the microbiota-gut-brain axis. Adv Exp Med Biol. 2014;817:195-219.

80. Gordon Cooke JB, Costello M. Newly identified vitamin Kproducing bacteria isolated from the neonatal faecal flora. Microb Ecol Health Dis. 2006;18:133-8.

81. LeBlanc JG, Laino JE, del Valle MJ, Vannini V, van Sinderen D, Taranto MP, et al. B-group vitamin production by lactic acid bacteria--current knowledge and potential applications. J Appl Microbiol. 2011;111:1297-309.

82. Sathyanarayanan Jayashree KJ, Kalaichelvan Gurumurthy. Isolation, screening and characterization of riboflavin producing lactic acid bacteria from Katpadi, Vellore District. Recent Res Sci Technol. 2010;2:83-88. 
83. Kuipers F, Claudel T, Sturm E, Staels B. The Farnesoid X Receptor (FXR) as modulator of bile acid metabolism. Rev Endocr Metab Disord. 2004;5:319-26.

84. Ridlon JM, Kang DJ, Hylemon PB. Bile salt biotransformations by human intestinal bacteria. J Lipid Res. 2006;47:241-59.

85. Hu Z, Ren L, Wang C, Liu B, Song G. Effect of chenodeoxycholic acid on fibrosis, inflammation and oxidative stress in kidney in high-fructose-fed Wistar rats. Kidney Blood Press Res. 2012;36:85-97.

86. Carbonero F, Gaskins HR. Sulfate-reducing bacteria in the human gut microbiome. In: Nelson KE, editor. Encyclopedia of metagenomics. New York, NY: Springer New York; 2013. p. $1-3$.

87. Aminzadeh MA, Vaziri ND. Downregulation of the renal and hepatic hydrogen sulfide (H2S)-producing enzymes and capacity in chronic kidney disease. Nephrol Dial Transplant. 2012;27: 498-504

88. Song K, Wang F, Li Q, Shi YB, Zheng HF, Peng H, et al. Hydrogen sulfide inhibits the renal fibrosis of obstructive nephropathy. Kidney Int. 2014;85:1318-29.

89. Perna AF, Lanza D, Sepe I, Raiola I, Capasso R, De Santo NG, et al. Hydrogen sulfide, a toxic gas with cardiovascular properties in uremia: how harmful is it? Blood Purif. 2011;31:102-6.

90. Tanida M, Yamano T, Maeda K, Okumura N, Fukushima Y, Nagai K. Effects of intraduodenal injection of Lactobacillus johnsonii La1 on renal sympathetic nerve activity and blood pressure in urethane-anesthetized rats. Neurosci Lett. 2005;389: 109-14.

91. Ait-Belgnaoui A, Han W, Lamine F, Eutamene H, Fioramonti J, Bueno L, et al. Lactobacillus farciminis treatment suppresses stress induced visceral hypersensitivity: a possible action through interaction with epithelial cell cytoskeleton contraction. Gut. 2006;55:1090-4.

92. Bercik P, Park AJ, Sinclair D, Khoshdel A, Lu J, Huang X, et al. The anxiolytic effect of Bifidobacterium longum NCC3001 involves vagal pathways for gut-brain communication. Neurogastroenterol Motil. 2011;23:1132-9.

93. Bravo JA, Forsythe P, Chew MV, Escaravage E, Savignac HM, Dinan TG, et al. Ingestion of Lactobacillus strain regulates emotional behavior and central GABA receptor expression in a mouse via the vagus nerve. Proc Natl Acad Sci USA. 2011;108:16050-5.

94. Eutamene H, Lamine F, Chabo C, Theodorou V, Rochat F, Bergonzelli GE, et al. Synergy between Lactobacillus paracasei and its bacterial products to counteract stress-induced gut permeability and sensitivity increase in rats. J Nutr. 2007;137: 1901-7.

95. Ma X, Mao YK, Wang B, Huizinga JD, Bienenstock J, Kunze W. Lactobacillus reuteri ingestion prevents hyperexcitability of colonic DRG neurons induced by noxious stimuli. Am J Physiol Gastrointest Liver Physiol. 2009;296:G868-75.

96. Rousseaux C, Thuru X, Gelot A, Barnich N, Neut C, Dubuquoy $\mathrm{L}$, et al. Lactobacillus acidophilus modulates intestinal pain and induces opioid and cannabinoid receptors. Nat Med. 2007;13:35-37.

97. Borovikova LV, Ivanova S, Zhang M, Yang H, Botchkina GI, Watkins LR, et al. Vagus nerve stimulation attenuates the systemic inflammatory response to endotoxin. Nature. 2000;405: 458-62.

98. Kimura I, Inoue D, Maeda T, Hara T, Ichimura A, Miyauchi S, et al. Short-chain fatty acids and ketones directly regulate sympathetic nervous system via $G$ protein-coupled receptor 41 (GPR41). Proc Natl Acad Sci USA. 2011;108:8030-5.

99. McCafferty DM, Wallace JL, Sharkey KA. Effects of chemical sympathectomy and sensory nerve ablation on experimental colitis in the rat. Am J Physiol. 1997;272:G272-280.
100. Schicho R, Krueger D, Zeller F, Von Weyhern CW, Frieling T, Kimura $\mathrm{H}$, et al. Hydrogen sulfide is a novel prosecretory neuromodulator in the Guinea-pig and human colon. Gastroenterology. 2006;131:1542-52.

101. Evenepoel P, Poesen R, Meijers B. The gut-kidney axis. Pediatr Nephrol. 2016;32:2005-14.

102. Felizardo RJ, Castoldi A, Andrade-Oliveira V, Camara NO. The microbiota and chronic kidney diseases: a double-edged sword. Clin Transl Immunol. 2016;5:e86.

103. Kikuchi M, Ueno M, Itoh Y, Suda W, Hattori M. Uremic toxinproducing gut microbiota in rats with chronic kidney disease. Nephron. 2017;135:51-60.

104. Sampaio-Maia B, Simoes-Silva L, Pestana M, Araujo R, SoaresSilva IJ. The role of the gut microbiome on chronic kidney disease. Adv Appl Microbiol. 2016;96:65-94.

105. Vianna HR, Soares CM, Tavares MS, Teixeira MM, Silva AC. [Inflammation in chronic kidney disease: the role of cytokines]. J Bras Nefrol. 2011;33:351-64.

106. Amdur RL, Feldman HI, Gupta J, Yang W, Kanetsky P, Shlipak $\mathrm{M}$, et al. Inflammation and progression of CKD: the CRIC study. Clin J Am Soc Nephrol. 2016;11:1546-56.

107. Stephenson M, Rowatt E. The production of acetylcholine by a strain of Lactobacillus plantarum. J Gen Microbiol. 1947;1: 279-98.

108. Truong LD, Trostel J, Garcia GE. Absence of nicotinic acetylcholine receptor alpha7 subunit amplifies inflammation and accelerates onset of fibrosis: an inflammatory kidney model. FASEB J. 2015;29:3558-70.

109. Kobayashi M, Mikami D, Kimura H, Kamiyama K, Morikawa Y, Yokoi S, et al. Short-chain fatty acids, GPR41 and GPR43 ligands, inhibit TNF-alpha-induced MCP-1 expression by modulating p38 and JNK signaling pathways in human renal cortical epithelial cells. Biochem Biophys Res Commun. 2017;486: 499-505.

110. Barrett E, Ross RP, O'Toole PW, Fitzgerald GF, Stanton C. gamma-Aminobutyric acid production by culturable bacteria from the human intestine. J Appl Microbiol. 2012;113:411-7.

111. Salman IM, Sarma Kandukuri D, Harrison JL, Hildreth CM, Phillips JK. Direct conscious telemetry recordings demonstrate increased renal sympathetic nerve activity in rats with chronic kidney disease. Front Physiol. 2015;6:218.

112. Chen $\mathrm{CH}$, Yang WC, Hsiao YH, Huang SC, Huang YC. High homocysteine, low vitamin B-6, and increased oxidative stress are independently associated with the risk of chronic kidney disease. Nutrition. 2016;32:236-41.

113. Streja E, Kovesdy CP, Streja DA, Moradi H, Kalantar-Zadeh K, Kashyap ML. Niacin and progression of CKD. Am J Kidney Dis. 2015;65:785-98.

114. Pastore A, Noce A, Di Giovamberardino G, De Stefano A, Calla $\mathrm{C}$, Zenobi R, et al. Homocysteine, cysteine, folate and vitamin B (1)(2) status in type 2 diabetic patients with chronic kidney disease. J Nephrol. 2015;28:571-6.

115. Schmidt RJ, Baylis C. Total nitric oxide production is low in patients with chronic renal disease. Kidney Int. 2000;58:1261-6.

116. Pal GK, Pal P, Nanda N, Amudharaj D, Adithan C. Cardiovascular dysfunctions and sympathovagal imbalance in hypertension and prehypertension: physiological perspectives. Future Cardiol. 2013;9:53-69.

117. Fujimura S, Shimakage H, Tanioka H, Yoshida M, SuzukiKusaba M, Hisa H, et al. Effects of GABA on noradrenaline release and vasoconstriction induced by renal nerve stimulation in isolated perfused rat kidney. Br J Pharmacol. 1999;127: 109-14.

118. Wierema TK, Houben AJ, de Leeuw PW. Acetylcholine-induced vasodilatation in the human hypertensive kidney: inhibition by muscarinic receptor antagonism. J Hypertens. 1997;15:1649-51. 
119. Skov J. Effects of GLP-1 in the kidney. Rev Endocr Metab Disord. 2014;15:197-207.

120. Skov J, Dejgaard A, Frokiaer J, Holst JJ, Jonassen T, Rittig S, et al. Glucagon-like peptide-1 (GLP-1): effect on kidney hemodynamics and renin-angiotensin-aldosterone system in healthy men. J Clin Endocrinol Metab. 2013;98:E664-671.

121. Bischoff A, Avramidis P, Erdbrugger W, Munter K, Michel MC. Receptor subtypes Y1 and Y5 are involved in the renal effects of neuropeptide Y. Br J Pharmacol. 1997;120:1335-43.

122. Pluznick JL, Protzko RJ, Gevorgyan H, Peterlin Z, Sipos A, Han $\mathrm{J}$, et al. Olfactory receptor responding to gut microbiota-derived signals plays a role in renin secretion and blood pressure regulation. Proc Natl Acad Sci USA. 2013;110:4410-5.

123. Natarajan N, Hori D, Flavahan S, Steppan J, Flavahan NA, Berkowitz DE, et al. Microbial short chain fatty acid metabolites lower blood pressure via endothelial G-protein coupled receptor 41. Physiol Genomics 2016;48:826-34.

124. Pluznick J. A novel SCFA receptor, the microbiota, and blood pressure regulation. Gut Microbes. 2014;5:202-7.

125. Parekh N, Dobrowolski L, Zou AP, Steinhausen M. Nitric oxide modulates angiotensin II- and norepinephrine-dependent vasoconstriction in rat kidney. Am J Physiol. 1996;270:R630-635.

126. O'Mahony SM, Clarke G, Borre YE, Dinan TG, Cryan JF. Serotonin, tryptophan metabolism and the brain-gut-microbiome axis. Behav Brain Res. 2015;277:32-48.

127. Yano JM, Yu K, Donaldson GP, Shastri GG, Ann P, Ma L, et al. Indigenous bacteria from the gut microbiota regulate host serotonin biosynthesis. Cell. 2015;161:264-76.

128. Takahashi T, Hisa H, Satoh S. Serotonin-induced renin release in the dog kidney. Eur J Pharmacol. 1991;193:315-20.

129. Li T, Croce K, Winquist RJ. Vasoconstrictor and vasodilator effects of serotonin in the isolated rabbit kidney. J Pharmacol Exp Ther. 1992;263:928-32.

130. Tuncer M, Vanhoutte PM. Serotonin releases a vasoconstrictor prostanoid in the kidney of the aging spontaneously hypertensive rat. Blood Press. 1993;2:142-5.

131. Dean C, Kampine JP. A role for serotonin in the elaboration of a differential pattern of activity in sympathetic nerves to kidney and skeletal muscle vasculature. J Auton Nerv Syst. 1993;44: 207-15.

132. Mitani S, Yabuki A, Taniguchi K, Yamato O. Association between the intrarenal renin-angiotensin system and renal injury in chronic kidney disease of dogs and cats. J Vet Med Sci. 2013;75:127-33.

133. Malekmakan L, Malekmakan A, Daneshian A, Pakfetrat M, Roosbeh J. Hypertension and diabetes remain the main causes of chronic renal failure in Fars Province, Iran 2013. Saudi J Kidney Dis Transplant. 2016;27:423-4.

134. Cook PR, Malmqvist LA, Bengtsson M, Tryggvason B, Lofstrom JB. Vagal and sympathetic activity during spinal analgesia. Acta Anaesthesiol Scand. 1990;34:271-5.

135. Reimann M, Hamer M, Schlaich MP, Malan NT, Ruediger H, Ziemssen $\mathrm{T}$, et al. Greater cardiovascular reactivity to a cold stimulus is due to higher cold pain perception in black Africans: the Sympathetic Activity and Ambulatory Blood Pressure in Africans (SABPA) study. J Hypertens. 2012;30:2416-24.

136. Narita K, Murata T, Hamada T, Takahashi T, Omori M, Suganuma $\mathrm{N}$, et al. Interactions among higher trait anxiety, sympathetic activity, and endothelial function in the elderly. J Psychiatr Res. 2007;41:418-27.

137. Moynes DM, Lucas GH, Beyak MJ, Lomax AE. Effects of inflammation on the innervation of the colon. Toxicol Pathol. 2014;42:111-7.

138. Kiuchi MG, Chen S. Improvement of renal function after renal sympathetic denervation in CKD patients with controlled vs. uncontrolled hypertension. Int J Cardiol. 2016;223:494-6.
139. Lau WL, Vaziri ND. Urea, a true uremic toxin: the empire strikes back. Clin Sci (Lond). 2017;131:3-12.

140. Kobori H, Ohashi N, Katsurada A, Miyata K, Satou R, Saito T, et al. Urinary angiotensinogen as a potential biomarker of severity of chronic kidney diseases. J Am Soc Hypertens. 2008;2:349-54.

141. Anguiano L, Riera M, Pascual J, Valdivielso JM, Barrios C, Betriu A, et al. Circulating angiotensin-converting enzyme 2 activity in patients with chronic kidney disease without previous history of cardiovascular disease. Nephrol Dial Transplant. 2015;30:1176-85.

142. Panjeta M, Tahirovic I, Sofic E, Coric J, Dervisevic A. Interpretation of erythropoietin and haemoglobin levels in patients with various stages of chronic kidney disease. J Med Biochem. 2017;36:145-52.

143. Cunningham J, Locatelli F, Rodriguez M. Secondary hyperparathyroidism: pathogenesis, disease progression, and therapeutic options. Clin J Am Soc Nephrol. 2011;6:913-21.

144. Liu TJ, Shi YY, Wang EB, Zhu T, Zhao Q. AT1R blocker losartan attenuates intestinal epithelial cell apoptosis in a mouse model of Crohn's disease. Mol Med Rep. 2016;13: $1156-62$.

145. Kim S, Wang G, Lobaton G, Li E, Yang T, Raizada M. Os 05-10 the microbial metabolite, butyrate attenuates angiotensin IIinduced hypertension and dysbiosis. J Hypertens. 2016;34: e60-1.

146. Perlot T, Penninger JM. ACE2 - from the renin-angiotensin system to gut microbiota and malnutrition. Microbes Infect. 2013;15:866-73.

147. Shiou SR, Yu Y, Chen S, Ciancio MJ, Petrof EO, Sun J, et al. Erythropoietin protects intestinal epithelial barrier function and lowers the incidence of experimental neonatal necrotizing enterocolitis. J Biol Chem. 2011;286:12123-32.

148. Dimitrov V, White JH. Vitamin D signaling in intestinal innate immunity and homeostasis. Mol Cell Endocrinol 2017;453: 68-78.

149. Serino M, Blasco-Baque V, Nicolas S, Burcelin R. Far from the eyes, close to the heart: dysbiosis of gut microbiota and cardiovascular consequences. Curr Cardiol Rep. 2014;16:540.

150. Sandek A, Bauditz J, Swidsinski A, Buhner S, Weber-Eibel J, von Haehling $S$, et al. Altered intestinal function in patients with chronic heart failure. J Am Coll Cardiol. 2007;50:1561-9.

151. Karlsson FH, Fak F, Nookaew I, Tremaroli V, Fagerberg B, Petranovic D, et al. Symptomatic atherosclerosis is associated with an altered gut metagenome. Nat Commun. 2012;3:1245.

152. Koren O, Spor A, Felin J, Fak F, Stombaugh J, Tremaroli V, et al. Human oral, gut, and plaque microbiota in patients with atherosclerosis. Proc Natl Acad Sci USA. 2011;108(Suppl 1):4592-8.

153. Li J, Zhao F, Wang Y, Chen J, Tao J, Tian G, et al. Gut microbiota dysbiosis contributes to the development of hypertension. Microbiome. 2017;5:14.

154. Kamo T, Akazawa H, Suda W, Saqa-Kamo A, Shimizu Y, Yaqi $\mathrm{H}$, et al. Dysbiosis and compositional alterations with aging in the gut microbiota of patients with heart failure. PLOS ONE. 2017;12:e0174099

155. Adnan S, Nelson JW, Ajami NJ, Venna VR, Petrosino JF, Bryan $\mathrm{RM}$, et al. Alterations in the gut microbiota can elicit hypertension in rats. Physiol Genom. 2017;49:96-104.

156. Al Khodor S, Reichert B, Shatat IF. The microbiome and blood pressure: can microbes regulate our blood pressure? Front Pediatr. 2017;5:138.

157. Lopez-Candales A, Hernandez Burgos PM, Hernandez-Suarez DF, Harris D. Linking chronic inflammation with cardiovascular disease: from normal aging to the metabolic syndrome. J Nat Sci. 2017;3:e341. 
158. Org E, Mehrabian M, Lusis AJ. Unraveling the environmental and genetic interactions in atherosclerosis: central role of the gut microbiota. Atherosclerosis. 2015;241:387-99.

159. Rogler G, Rosano G. The heart and the gut. Eur Heart J. 2014;35:426-30.

160. Pucino V, Bombardieri M, Pitzalis C, Mauro C. Lactate at the crossroads of metabolism, inflammation, and autoimmunity. Eur J Immunol. 2017;47:14-21.

161. Juraschek SP, Bower JK, Selvin E, Subash Shantha GP, Hoogeveen RC, Ballantyne CM, et al. Plasma lactate and incident hypertension in the atherosclerosis risk in communities study. Am J Hypertens. 2015;28:216-24.

162. Solak Y, Afsar B, Vaziri ND, Aslan G, Yalcin CE, Covic A, et al. Hypertension as an autoimmune and inflammatory disease. Hypertens Res. 2016;39:567-73.

163. Guo J, Lu L, Hua Y, Huang K, Wang I, Huang L, et al. Vasculopathy in the setting of cardiorenal syndrome: roles of protein-bound uremic toxins. Am J Physiol Heart Circ Physiol. 2017;313:H1-13

164. Tang WH, Hazen SL. The contributory role of gut microbiota in cardiovascular disease. J Clin Invest. 2014;124:4204-11.

165. Koeth RA, Levison BS, Culley MK, Buffa JA, Wang Z, Gregory $\mathrm{JC}$, et al. gamma-Butyrobetaine is a proatherogenic intermediate in gut microbial metabolism of L-carnitine to TMAO. Cell Metab. 2014;20:799-812.

166. Goldsmith JR, Sartor RB. The role of diet on intestinal microbiota metabolism: downstream impacts on host immune function and health, and therapeutic implications. J Gastroenterol. 2014;49:785-98.

167. Wei SG, Yu Y, Zhang ZH, Felder RB. Proinflammatory cytokines upregulate sympathoexcitatory mechanisms in the subfornical organ of the rat. Hypertension. 1979;2015:1126-33.

168. Li DP, Pan HL. Role of gamma-aminobutyric acid (GABA)A and $\mathrm{GABAB}$ receptors in paraventricular nucleus in control of sympathetic vasomotor tone in hypertension. J Pharmacol Exp Ther. 2007;320:615-26.

169. Marcil V, Delvin E, Seidman E, Poitras L, Zoltowska M, Garofalo C, et al. Modulation of lipid synthesis, apolipoprotein biogenesis, and lipoprotein assembly by butyrate. Am J Physiol Gastrointest Liver Physiol. 2002;283:G340-6.

170. Cryan JF, Dinan TG. Mind-altering microorganisms: the impact of the gut microbiota on brain and behaviour. Nat Rev Neurosci. 2012;13:701-12.

171. Nichols CD. Serotonin 5-HT(2A) receptor function as a contributing factor to both neuropsychiatric and cardiovascular diseases. Cardiovasc Psychiatry Neurol. 2009;2009:475108.

172. Penesova A, Radikova Z, Cizmarova E, Kvetnansky R, Blazicek $\mathrm{P}$, Vlcek $\mathrm{M}$, et al. The role of norepinephrine and insulin resistance in an early stage of hypertension. Ann NY Acad Sci. 2008;1148:490-4

173. Liu S, Li Y, Zhang Z, Xie F, Xu Q, Huang X, et al. alpha1Adrenergic receptors mediate combined signals initiated by mechanical stretch stress and norepinephrine leading to accelerated mouse vein graft atherosclerosis. J Vasc Surg. 2013;57:1645-56, 1656.e1641-3

174. Cuevas S, Villar VA, Jose PA, Armando I. Renal dopamine receptors, oxidative stress, and hypertension. Int J Mol Sci. 2013;14:17553-72.

175. Yasunari K, Kohno M, Kano H, Yokokawa K, Minami M, Yoshikawa J. Vascular dopamine-I receptors and atherosclerosis. J Atheroscler Thromb. 1997;4:59-64.

176. Tjeerdsma G, van Wijk LM, Molhoek GP, Boomsma F, Haaksma J, van Veldhuisen DJ. Autonomic and hemodynamic effects of a new selective dopamine agonist, CHF1035, in patients with chronic heart failure. Cardiovasc Drugs Ther. 2001;15:139-45.
177. Li J, Zheng J, Wang S, Lau HK, Fathi A, Wang Q. Cardiovascular benefits of native GLP-1 and its metabolites: an indicator for GLP-1-therapy strategies. Front Physiol. 2017;8:15.

178. Angelone T, Filice E, Quintieri AM, Imbrogno S, Amodio N, Pasqua $\mathrm{T}$, et al. Receptor identification and physiological characterisation of glucagon-like peptide-2 in the rat heart. Nutr Metab Cardiovasc Dis. 2012;22:486-94.

179. Lutz TA, Osto E. Glucagon-like peptide-1, glucagon-like peptide-2, and lipid metabolism. Curr Opin Lipidol. 2016;27: 257-63.

180. Ansar S, Koska J, Reaven PD. Postprandial hyperlipidemia, endothelial dysfunction and cardiovascular risk: focus on incretins. Cardiovasc Diabetol. 2011;10:61.

181. Smith RM, Klein R, Kruzliak P, Zulli A. Role of peptide YY in blood vessel function and atherosclerosis in a rabbit model. Clin Exp Pharmacol Physiol. 2015;42:648-52.

182. Zhu X, Gillespie DG, Jackson EKNPY1-36. and PYY1-36 activate cardiac fibroblasts: an effect enhanced by genetic hypertension and inhibition of dipeptidyl peptidase 4. Am J Physiol Heart Circ Physiol. 2015;309:H1528-42.

183. Grassi G, Ram VS. Evidence for a critical role of the sympathetic nervous system in hypertension. $J$ Am Soc Hypertens. 2016;10:457-66.

184. Gregorio PC, Favretto G, Sassaki GL, Cunha RS, Becker-Finco A, Pecoits-Filho R, et al. Sevelamer reduces endothelial inflammatory response to advanced glycation end products. Clin Kidney J. 2018;11:89-98.

185. Liu J, Huang K, Cai GY, Chen XM, Yang JR, Lin LR, et al. Receptor for advanced glycation end-products promotes premature senescence of proximal tubular epithelial cells via activation of endoplasmic reticulum stress-dependent p21 signaling. Cell Signal. 2014;26:110-21.

186. Stinghen AE, Massy ZA, Vlassara H, Striker GE, Boullier A. Uremic toxicity of advanced glycation end products in CKD. J Am Soc Nephrol. 2016;27:354-70.

187. Vlassara H, Striker LJ, Teichberg S, Fuh H, Li YM, Steffes M. Advanced glycation end products induce glomerular sclerosis and albuminuria in normal rats. Proc Natl Acad Sci USA. 1994;91:11704-8.

188. Thomas MC, Woodward M, Neal B, Li Q, Pickering R, Marre M, et al. Relationship between levels of advanced glycation end products and their soluble receptor and adverse outcomes in adults with type 2 diabetes. Diabetes Care. 2015;38:1891-7.

189. Hartog JW, Voors AA, Bakker SJ, Smit AJ, van Veldhuisen DJ. Advanced glycation end-products (AGEs) and heart failure: pathophysiology and clinical implications. Eur J Heart Fail. 2007;9:1146-55.

190. Campbell DJ, Somaratne JB, Jenkins AJ, Prior DL, Yii M, Kenny JF, et al. Impact of type 2 diabetes and the metabolic syndrome on myocardial structure and microvasculature of men with coronary artery disease. Cardiovasc Diabetol. 2011;10:80.

191. Donaldson C, Taatjes DJ, Zile M, Palmer B, VanBuren P, Spinale $\mathrm{F}$, et al. Combined immunoelectron microscopic and computer-assisted image analyses to detect advanced glycation end-products in human myocardium. Histochem Cell Biol. 2010;134:23-30.

192. Faist V, Erbersdobler HF. Metabolic transit and in vivo effects of melanoidins and precursor compounds deriving from the Maillard reaction. Ann Nutr Metab. 2001;45:1-12.

193. Kellow NJ, Coughlan MT. Effect of diet-derived advanced glycation end products on inflammation. Nutr Rev. 2015;73: 737-59.

194. Ames JM, Wynne A, Hofmann A, Plos S, Gibson GR. The effect of a model melanoidin mixture on faecal bacterial populations in vitro. Br J Nutr. 1999;82:489-95. 
195. Yacoub R, Nugent M, Cai W, Nadkarni GN, Chaves LD, Abyad $\mathrm{S}$, et al. Advanced glycation end products dietary restriction effects on bacterial gut microbiota in peritoneal dialysis patients; a randomized open label controlled trial. PLoS ONE. 2017;12: e0184789.

196. Ou J, Huang J, Zhao D, Du B, Wang M. Protective effect of rosmarinic acid and carnosic acid against streptozotocin-induced oxidation, glycation, inflammation and microbiota imbalance in diabetic rats. Food Funct. 2018;9:851-60.

197. Battson ML, Lee DM, Jarrell DK, Hou S, Ecton KE, Weir TL, et al. Suppression of gut dysbiosis reverses Western diet-induced vascular dysfunction. Am J Physiol Endocrinol Metab. 2018; 314:E468-77.

198. Mastrocola R, Ferrocino I, Liberto E, Chiazza F, Cento AS, Collotta D, et al. Fructose liquid and solid formulations differently affect gut integrity, microbiota composition and related liver toxicity: a comparative in vivo study. J Nutr Biochem. 2018;55:185-99.

199. Qu W, Yuan X, Zhao J, Zhang Y, Hu J, Wang J, et al. Dietary advanced glycation end products modify gut microbial composition and partially increase colon permeability in rats. Mol Nutr Food Res. 2017. https://doi.org/10.1002/mnfr.201700118.

200. Clementi A, Virzi GM, Goh CY, Cruz DN, Granata A, Vescovo $\mathrm{G}$, et al. Cardiorenal syndrome type 4: a review. Cardiorenal Med. 2013;3:63-70.

201. Preeti J, Alexandre M, Pupalan I, Merlin TC, Claudio R. Chronic heart failure and comorbid renal dysfunction - a focus on type 2 cardiorenal syndrome. Curr Cardiol Rev. 2016;12:186-94.

202. Lekawanvijit $S$. Role of gut-derived protein-bound uremic toxins in cardiorenal syndrome and potential treatment modalities. Circ J. Society. 2015;79:2088-97.

203. Anders HJ, Andersen K, Stecher B. The intestinal microbiota, a leaky gut, and abnormal immunity in kidney disease. Kidney Int. 2013;83:1010-6.

204. Kato S, Chmielewski M, Honda H, Pecoits-Filho R, Matsuo S, Yuzawa Y, et al. Aspects of immune dysfunction in end-stage renal disease. Clin J Am Soc Nephrol. 2008;3:1526-33.

205. Hooper LV, Littman DR, Macpherson AJ. Interactions between the microbiota and the immune system. Science. 2012;336: 1268-73.

206. Chow J, Tang H, Mazmanian SK. Pathobionts of the gastrointestinal microbiota and inflammatory disease. Curr Opin Immunol. 2011;23:473-80.

207. Niebauer J, Volk HD, Kemp M, Dominguez M, Schumann RR, Rauchhaus M, et al. Endotoxin and immune activation in chronic heart failure: a prospective cohort study. Lancet. 1999;353: $1838-42$.

208. Wang F, Zhang P, Jiang H, Cheng S. Gut bacterial translocation contributes to microinflammation in experimental uremia. Dig Dis Sci. 2012;57:2856-62.

209. Kiechl S, Lorenz E, Reindl M, Wiedermann CJ, Oberhollenzer F, Bonora E, et al. Toll-like receptor 4 polymorphisms and atherogenesis. N Engl J Med. 2002;347:185-92.

210. Niwa T. Role of indoxyl sulfate in the progression of chronic kidney disease and cardiovascular disease: experimental and clinical effects of oral sorbent AST-120. Ther Apher Dial. 2011;15:120-4.

211. Li T, Gua C, Wu B, Chen Y. Increased circulating trimethylamine N-oxide contributes to endothelial dysfunction in a rat model of chronic kidney disease. Biochem Biophys Res Commun. 2018;495:2071-7.

212. Borges NA, Barros AF, Nakao LS, Dolenga CJ, Fouque D, Mafra D. Protein-bound uremic toxins from gut microbiota and inflammatory markers in chronic kidney disease. J Ren Nutr. 2016;26:396-400.
213. Mafra D, Fouque D. Gut microbiota and inflammation in chronic kidney disease patients. Clin Kidney J. 2015;8:332-4.

214. Chan Q, Loo RL, Ebbels TM, Van Horn L, Daviglus ML, Stamler J, et al. Metabolic phenotyping for discovery of urinary biomarkers of diet, xenobiotics and blood pressure in the INTERMAP Study: an overview. Hypertens Res. 2017;40: 336-45.

215. van Baarlen $\mathrm{P}$, Troost FJ, van Hemert $\mathrm{S}$, van der Meer C, de Vos WM, de Groot PJ, et al. Differential NF-kappaB pathways induction by Lactobacillus plantarum in the duodenum of healthy humans correlating with immune tolerance. Proc Natl Acad Sci USA. 2009;106:2371-6.

216. Rastall RA, Gibson GR, Gill HS, Guarner F, Klaenhammer TR, Pot B, et al. Modulation of the microbial ecology of the human colon by probiotics, prebiotics and synbiotics to enhance human health: an overview of enabling science and potential applications. FEMS Microbiol Ecol. 2005;52:145-52.

217. Chen L, Liu W, Li Y, Luo S, Liu Q, Zhong Y, et al. Lactobacillus acidophilus ATCC 4356 attenuates the atherosclerotic progression through modulation of oxidative stress and inflammatory process. Int Immunopharmacol. 2013;17:108-15.

218. Wang IK, Wu YY, Yang YF, Ting IW, Lin CC, Yen TH, et al. The effect of probiotics on serum levels of cytokine and endotoxin in peritoneal dialysis patients: a randomised, double-blind, placebo-controlled trial. Benef Microbes. 2015;6:423-30.

219. Brugere JF, Borrel G, Gaci N, Tottey W, O'Toole PW, Malpuech-Brugere C. Archaebiotics: proposed therapeutic use of archaea to prevent trimethylaminuria and cardiovascular disease. Gut Microbes. 2014;5:5-10.

220. Wu GD, Chen J, Hoffmann C, Bittinger K, Chen YY, Keilbaugh SA, et al. Linking long-term dietary patterns with gut microbial enterotypes. Science. 2011;334:105-8.

221. Klinder A, Shen Q, Heppel S, Lovegrove JA, Rowland I, Tuohy KM. Impact of increasing fruit and vegetables and flavonoid intake on the human gut microbiota. Food Funct. 2016;7: 1788-96.

222. Richter CK, Skulas-Ray AC, Champagne CM, Kris-Etherton PM. Plant protein and animal proteins: do they differentially affect cardiovascular disease risk? Adv Nutr. 2015;6:712-28.

223. Silk DB, Davis A, Vulevic J, Tzortzis G, Gibson GR. Clinical trial: the effects of a trans-galactooligosaccharide prebiotic on faecal microbiota and symptoms in irritable bowel syndrome. Aliment Pharmacol Ther. 2009;29:508-18.

224. Krishnamurthy VM, Wei G, Baird BC, Murtaugh M, Chonchol $\mathrm{MB}$, Raphael KL, et al. High dietary fiber intake is associated with decreased inflammation and all-cause mortality in patients with chronic kidney disease. Kidney Int. 2012;81:300-6.

225. Vaziri ND, Liu SM, Lau WL, Khazaeli M, Nazertehrani S, Farzaneh SH, et al. High amylose resistant starch diet ameliorates oxidative stress, inflammation, and progression of chronic kidney disease. PLoS ONE. 2014;9:e114881.

226. Tome-Carneiro J, Visioli F. Polyphenol-based nutraceuticals for the prevention and treatment of cardiovascular disease: review of human evidence. Phytomedicine. 2016;23:1145-74.

227. Cantarel BL, Waubant E, Chehoud C, Kuczynski J, DeSantis TZ, Warrington $\mathrm{J}$, et al. Gut microbiota in multiple sclerosis: possible influence of immunomodulators. J Invest Med. 2015;63: 729-34.

228. Shao Y, Lei Z, Yuan J, Yang Y, Guo Y, Zhang B. Effect of zinc on growth performance, gut morphometry, and cecal microbial community in broilers challenged with Salmonella enterica serovar typhimurium. J Microbiol. 2014;52:1002-11.

229. Dostal A, Lacroix C, Bircher L, Pham VT, Follador R, Zimmermann $\mathrm{MB}$, et al. Iron modulates butyrate production by a child gut microbiota in vitro. mBio. 2015;6:e01453-01415. 
230. Hawrelak JA, Cattley T, Myers SP. Essential oils in the treatment of intestinal dysbiosis: a preliminary in vitro study. Altern Med Rev: a J Clin Ther. 2009;14:380-4.

231. Yu HN, Zhu J, Pan WS, Shen SR, Shan WG, Das UN. Effects of fish oil with a high content of n-3 polyunsaturated fatty acids on mouse gut microbiota. Arch Med Res. 2014;45:195-202.

232. Zhu HL, Liu YL, Xie XL, Huang JJ, Hou YQ. Effect of Larginine on intestinal mucosal immune barrier function in weaned pigs after Escherichia coli LPS challenge. Innate Immun. 2013;19:242-52.

233. McCreight LJ, Bailey CJ, Pearson ER. Metformin and the gastrointestinal tract. Diabetologia. 2016;59:426-35.

234. Napolitano A, Miller S, Nicholls AW, Baker D, Van Horn S, Thomas E, et al. Novel gut-based pharmacology of metformin in patients with type 2 diabetes mellitus. PLoS ONE. 2014;9:e100778.

235. Wang L, Li P, Tang Z, Yan X, Feng B. Structural modulation of the gut microbiota and the relationship with body weight: compared evaluation of liraglutide and saxagliptin treatment. Sci Rep. 2016;6:33251.

236. Mishima E, Fukuda S, Shima H, Hirayama A, Akiyama Y, Takeuchi Y, et al. Alteration of the intestinal environment by lubiprostone is associated with amelioration of adenine-induced CKD. J Am Soc Nephrol. 2015;26:1787-94.

237. Zeng YQ, Dai Z, Lu F, Lu Z, Liu X, Chen C, et al. Emodin via colonic irrigation modulates gut microbiota and reduces uremic toxins in rats with chronic kidney disease. Oncotarget. 2016;7: 17468-78.

238. Zhang X, Fang Z, Zhang C, Xia H, Jie Z, Han X, et al. Effects of acarbose on the gut microbiota of prediabetic patients: a randomized, double-blind, controlled crossover trial. Diabetes Ther. 2017;8:293-307.

239. Montandon SA, Jornayvaz FR. Effects of antidiabetic drugs on gut microbiota composition. Genes (Basel) 2017;8:E250.

240. Khan TJ, Ahmed YM, Zamzami MA, Siddiqui AM, Khan I, Baothman OAS, et al. Atorvastatin treatment modulates the gut microbiota of the hypercholesterolemic patients. OMICS. 2018;22:154-63.

241. Catry E, Pachikian BD, Salazar N, Neyrinck AM, Cani PD, Delzenne NM. Ezetimibe and simvastatin modulate gut microbiota and expression of genes related to cholesterol metabolism. Life Sci. 2015;132:77-84.

242. Costabile A, Buttarazzi I, Kolida S, Quercia S, Baldini J, Swann JR, et al. An in vivo assessment of the cholesterol- lowering efficacy of Lactobacillus plantarum ECGC 13110402 in normal to mildly hypercholesterolaemic adults. PLoS ONE. 2017;12:e0187964.

243. Robles-Vera I, Toral M, Romero M, Jimenez R, Sanchez M, Perez-Vizcaino F, et al. Antihypertensive effects of probiotics. Curr Hypertens Rep. 2017;19:26.

244. Monda V, Villano I, Messina A, Valenzano A, Esposito T, Moscatelli F. et al. Exercise modifies the gut microbiota with positive health effects. Oxid Med Cell Longev. 2017;2017: 3831972

245. Delbes AS, Castel J, Denis RGP, Morel C, Quinones M, Everard A, et al. Prebiotics supplementation impact on the reinforcing and motivational aspect of feeding. Front Endocrinol (Lausanne). 2018;9:273

246. Bauer PV, Hamr SC, Duca FA. Regulation of energy balance by a gut-brain axis and involvement of the gut microbiota. Cell Mol Life Sci. 2016;73:737-55.

247. Lyte M. Microbial endocrinology: host-microbiota neuroendocrine interactions influencing brain and behavior. Gut Microbes. 2014;5:381-9.

248. Cani PD, Joly E, Horsmans Y, Delzenne NM. Oligofructose promotes satiety in healthy human: a pilot study. Eur J Clin Nutr. 2006;60:567-72.

249. Mack I, Cuntz U, Gramer C, Niedermaier S, Pohl C, Schwiertz A, et al. Weight gain in anorexia nervosa does not ameliorate the faecal microbiota, branched chain fatty acid profiles, and gastrointestinal complaints. Sci Rep. 2016;6: 26752.

250. Dinan TG, Cryan JF. Melancholic microbes: a link between gut microbiota and depression?. Neurogastroenterol Motil. 2013;25: 713-9.

251. Ramezani A, Raj DS. The gut microbiome, kidney disease, and targeted interventions. J Am Soc Nephrol. 2014;25:657-70.

252. Nallu A, Sharma S, Ramezani A, Muralidharan J, Raj D. Gut microbiome in chronic kidney disease: challenges and opportunities. Transl Res. 2017;179:24-37.

253. Ellis RJ, Small DM, Vesey DA, Johnson DW, Francis R, Vitetta $\mathrm{L}$, et al. Indoxyl sulphate and kidney disease: causes, consequences and interventions. Nephrology (Carlton). 2016;21: $170-7$.

254. Abratt VR, Reid SJ. Oxalate-degrading bacteria of the human gut as probiotics in the management of kidney stone disease. Adv Appl Microbiol. 2010;72:63-87. 